V.

\title{
Zur Geschichte des ersten punischen Krieges.
}

Eine eingehendere Darstellung des ersten punischen Kriegs ist uns leider nicht erhalten, denn von Diodors Bericht sind nur Bruchstücke, von Livius' Erzählung nur kurze Inhaltsangaben auf uns gekommen. Unsere Kenntnis der Geschichte dieses so wechselvollen Ringens der beiden Mittelmeergroßmächte Rom und Karthago ist daher nur eine lückenhafte und beruht gröbtenteils auf der zusammenfassenden Uebersicht, die Polybius als Einleitung seinem Geschichtswerke vorausgehen läßt. Zwar besitzt seine Darstellung schon um deswillen hohen Wert, weil er von allen Erzählern den geschilderten Ereignissen am nächsten steht, aber einem Kriege, der 24 Jahre lang Roms und Karthagos Heer und Flotte in Anspruch nahm, sind nur 55 Kapitel gewidmet, und daraus ergiebt sich von selbst, dak wir nur in sehr summarischer Weise durch Polyb über die Wechselfälle eines so langwierigen Krieges unterrichtet werden können. Bei diesem Charakter unserer in erster Linie stehenden Quelle kann es nicht wunder nehmen, wenn wir in einer Reihe von Fragen im Zweifel gelassen werden und wenn weder über die benutzten Quellen, noch über die zeitliche Fixierung der einzelnen Begebenheiten die Ansichten der Forscher zu einer Einigung gelangt sind. Da auch die Behandlung, welche Meltzer in dem zweiten Bande seiner Geschichte der Karthager den schwebenden Fragen angedeihen läßt, nicht als endgültige Lösung derselben angesehen werden kann und da es, wie Soltau (Röm. Chronol. S. 208) mit Recht hervorhebt, an erschöpfenden Spezialuntersuchungen über den ersten punischen Krieg fehlt, so dürfte eine Wiederaufnahme derselben nicht unangebracht sein.

Wenden wir zunächst uns zur Besprechung einzelner chro- 
nologischer Fragen, so hatte ich (Jahrb. f. Phil. 1892 S. 105 ff.) die Schlacht am Longanosflusse in Uebereinstimmung mit anderen (s. Meltzer II S. 552) ins Jahr 265 gesetzt, um so den Widerspruch zu beseitigen, der sich daraus ergab, dafs zwischen der Besetzung Messanas durch die Karthager (270) und dem Eingreifen der Römer (264) ein Zwischenraum von 6 Jahren lag. Diese Annahme steht nach Meltzer in vollem Gegensatze zu den Quellen; er findet es nicht befremdend, wenn die Karthager schon 270 sich in den Besitz Messanas setzten, die Römer aber erst 264 zur Vertreibung derselben sich anschickten. „Man muf nur genau unterscheiden", so setzt er auseinander, „wo Polybius die Ereignisse nur kurz zusammenfassend bezeichnet und wo er einen bestimmten Synchronismus uns giebt. Zur letzteren Art gehört aber Polyb I 8, 2, und zwar so scharf, daf, da die Belagerung und Einnahme von Rhegium nach unabhängiger römischer Ueberlieferung in das Jahr 270 v. Chr. gehört, auch für Hieros Angriff und die Schlacht am Longanos mit ihren Folgen nur dieses in Betracht gezogen werden kann ". Hiergegen ist einzuwenden, dak von einem scharfen Synchronismus bei Polyb nicht die Rede sein kann, seine Worte besagen weiter nichts, als dak mit der Bestrafung der Kampaner in Rhegion auch die Mamertiner sogleich $\left(\pi \alpha \rho \grave{\alpha} \pi \delta ́ \delta \alpha_{\varsigma}\right)$ die Unterstützung ihrer früheren Verbündeten verloren und auf ihre Stadt zurückgedrängt wurden, während sie zuvor nicht nur ungestört im Besitze Messanas waren, sondern auch mit Karthagern und Syrakusanern um die Nachbarlande streiten und viele Teile Siziliens plündern konnten (I 8, 1). Dafs dieser Rückgang der Mamertinermacht mit einem Male, und nicht in einem etwa 4-5jährigen Zeitraum erfolgt sei, kann man nicht so ohne Weiteres den Worten Polybs entnehmen, vielmehr stehen Meltzers Ansätze im Widerspruch mit den Quellen, wenn Polyb I 10, 1 und 2 fortfährt: Von den Mamertinern, die früher, wie oben gesagt, der Hilfe seitens Rhegions beraubt waren, jetzt aber in ihrem eigenen Lande aus den erwähnten Gründen vollständig unterlagen, suchte die eine Partei Hilfe bei den Karthagern und bot ( $\varepsilon v \varepsilon \chi \varepsilon i p i \zeta o v)$ sich und ihre Stadt ihnen an, die andere schickte Gesandte zu den Römern, welche diesen Messana über- 
geben und sie, die Stammesgenossen, um Hilfe bitten sollten.

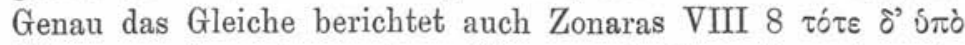

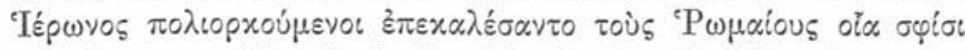
$\pi \rho \circ \sigma^{\prime} x o v \tau \alpha \varsigma$. Hier liegt ein viel schärferer Synchronismus vor als I 8, 2, wo man den Beginn des Verfalls der Mamertinermacht als gleichzeitig mit der Eroberung Rhegions ansehen mag, ohne dies aber von den im weiteren Verlauf eintretenden Ereignissen annehmen zu dürfen. Meltzer will auch den Hinweis auf die Bezeichnung Hierons als $\beta \alpha \sigma \iota \lambda$ sús bei Diodor XXII, 13 nicht gelten lassen: „Dafs der Ausdruck $\beta \alpha \sigma \lambda \lambda \varepsilon^{\prime} \varsigma_{\varsigma}$ schon für die Zeit vor der Schlacht am Longanos vorkommt, darf allerdings noch viel weniger betont werden, auch geschieht dies z. B. von Beloch nicht". Ich habe dies a. a. O. gethan und halte mich dazu auch für berechtigt, solange mir nicht nachgewiesen wird, weshalb dies nicht geschehen darf. Diodor bezeichnet $7 \mathrm{mal}$ Hiero als $\beta \alpha \sigma i \lambda$ عús in einem recht ausführlich erhaltenen Excerpte, das zweifellos auf gute Quelle (Philinos) zurückgeht und zu keinerlei Ausstellungen Anlak giebt. Weun bei Justin XXIII 4, 2 ut consentiente omnium civitatium favore dux adversus Carthaginienses primum, mox rex crearetur so scharf seine Stellung als dux von der als rex unterschieden wird, dann sind wir nicht berechtigt, Diodor oder seiner Quelle eine solche Vernachlässigung des Ausdrucks zuzuschreiben, wie dies von Meltzer geschieht. Nach Diodor war Hiero schon

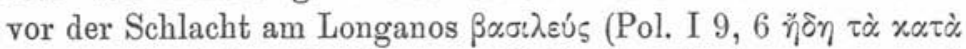

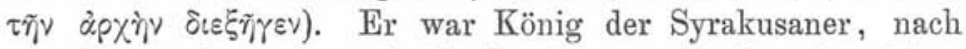
dem Siege erkannten auch die Bundesgenossen ihn als solchen

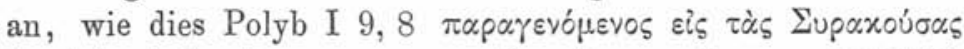

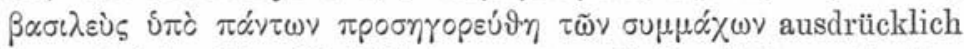
hervorhebt. Dies Verhältnis zu einer Reihe früher selbständiger Gemeinden bezeugt auch Diod. XXIII 4, 1 xupt-

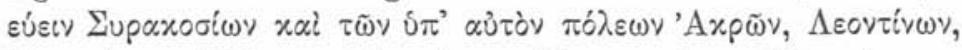

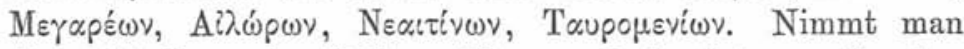
diese Scheidung der Stellung Hierons als $\beta \alpha \sigma \lambda \lambda \varepsilon u ́ \varsigma$ von Syrakus und als $\beta \alpha \sigma i \lambda \varepsilon u ́ s$ der Bundesgenossen nicht an, so muß man einen unlöslichen Widerspruch zwischen Diodor und Polyb gelten lassen. Hiero wurde 270 König der Syrakusaner, aber erst 265/4 nach dem Siege über die Mamertiner König der 
Bundesgenossen; nur dieser Ansatz steht im Einklang mit der Ueberlieferung.

Im Zusammenhang mit dieser chronologischen Frage mag die Veranlassung des punischen Kriegs hier Erörterung finden. Ueber dieselbe handelt Ranke Weltgeschichte Bd. III S. 170 und erkennt dem Berichte des Zonaras (Dion) vor dem Polybs den Vorrang zu. Dabei trägt er m. E. dem Umstande zu wenig Rechnung, daßs wir bei Polyb einen sehr gekürzten und darum nicht genügenden Auszug aus einer ausführlicheren Darstellung haben, daß wir seine Erzählung erst an der Hand anderer Darstellungen ergänzen müssen. Dies ist aber möglich, ohne dak ein so tiefgehender Gegensatz zwischen Polyb und Zonaras, wie Ranke ihn annimmt, zu Tage tritt. Festhalten muj man, dace Polyb I 10 und 11 nicht die beiden Momente, die er III 26, 6 scharf auseinander hält, scheidet:

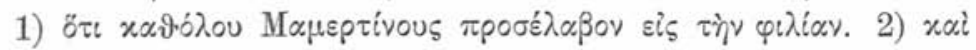

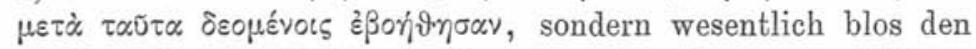

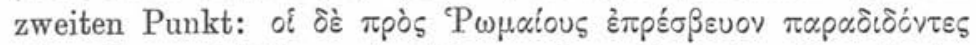

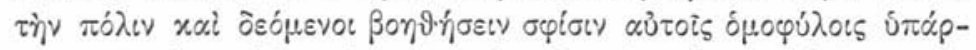
Xovorv im Auge hat, ohne jedoch seine Angaben auf diesen zu beschränken. Die Aufnahme der Mamertiner in die römische Bundesgenossenschaft fand zur Zeit der ersten Belagerung

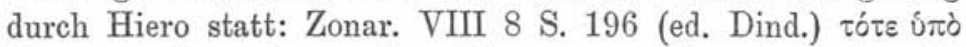

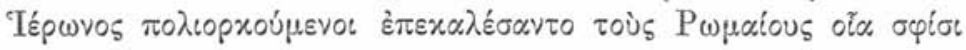

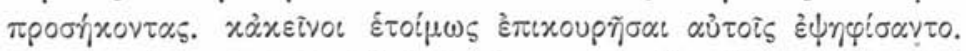
Der Senat wagte keine Entscheidung zu treffen (Polyb), dieselbe erfolgte vielmehr durch das Volk. Zu trennen ist davon der zweite Beschluf, der die Unterstützung der durch die Karthager und Hiero bedrängten und belagerten Mamertiner, somit die Aufnahme des Kriegs gegen die Karthager aussprach, er wurde vom Senate gefaßst zur Zeit, da Karthager und Hiero Messana belagerten: Liv. per. 17. contra quos et Hieronem regem auxilium Mamertinis ferendum censuit senatus, Oros. IV 7, 1 auxilia contra Hieronem regem et Poenorum copias Hieroni iunctas et Appium Claudium consulem cum exercitu misere Romani. So erledigt sich die Differenz zwischen Polybius und Livius, ersterer hält die beiden Beschlüsse nicht auseinander und übergeht alles, was zwischen ihnen liegt, und 
für diese Lücke haben die Fragmente Diodors ${ }^{1}$ ) und die Erzählung bei Zonaras einzutreten. Der Gang der Ereignisse ist folgender: Hiero belagerte Messana, und die Mamertiner wandten sich deshalb an Rom. Eine karthagische Flotte lag bei Lipara, ihr Führer, dessen Namen Diodor und Zonaras verschieden angeben, hielt die Mamertiner zurück, sich an Hiero zu ergeben, überlistete letztere und legte eine Besatzung in die Stadt. Obwohl Hiero zur Aufgabe der Belagerung sich gezwungen sah, schlof er doch, vielleicht durch das Verhalten der Römer und ihr Bündnis mit den Mamertinern verstimmt, mit letzteren und den Karthagern Frieden. In diesem Augenblicke griffen die Römer ein, der römische Tribun G. Claudius Appius traf in Rhegion ein und suchte zunächst auf dem Wege der Verhandlungen die Karthager zum Abzuge aus Messana zu bestimmen. Der erste Versuch war erfolglos. Da er sah, dafs die Mamertiner nicht den Römern unterthan sein wollten, andererseits aber über die Besatzung der Karthager ungehalten waren, erklärte er bei abermaligen Verhandlungen, die Römer hätten nur die Befreiung Messanas im Auge und würden nach Erreichung dieses Ziels abziehen. Damit gewann er die Mamertiner, ohne aber auf die Karthager Eindruck zu machen. Ein Versuch, mit seiner Flotte nach Messana überzusetzen, schlug fehl (Zonar. VIII 8 S. 197, Dio ed. Dind. S. 70, 7, Diod.

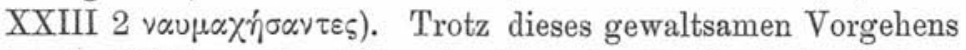
ist der Friede noch nicht gebrochen, der karthagische Führer gab die genommenen Schiffe zurück und forderte Claudius auf, Frieden zu halten, die Drohung hinzufügend, gegen den Willen der Karthager sollten die Römer nicht einmal ihre Hände im Meer waschen können (Diod. XXIII 2, Zonar. a. a. 0.). Ein zweiter Versuch des Claudius überzusetzen ist vom Glücke begünstigt, in einer Versammlung der Mamertiner wurde der karthagische Feldherr ergriffen, und die karthagische Besatzung gab Messana auf. Mit der Forderung, die Römer sollten bis zu einem bestimmten Tage Messana räumen und Sizilien verlassen, abgewiesen, begannen die Karthager den Krieg, Hanno sammelte ein Heer in Lilybaion und befestigte Agrigent. Mit

$\left.{ }^{1}\right)$ Auf die fehlerhafte Anordnung von XXIII 1 u. 2 bei Dindorf hat schon Meltzer aufmerksam gemacht. 
Hiero verbündet begannen sie darauf die Belagerung Messanas, zur Unterstützung der Stadt wurde der Konsul Appius Claudius abgesandt, der zunächst die Verhandlungen mit den Feinden noch weiterführte, ohne damit einen Erfolg zu erzielen.

Ranke legt besonderes Gewicht darauf, dafo Polyb von dem ersten Versuche der Römer nach Sizilien überzusetzen schweige, sowie von ihrer Erklärung, sie würden, wenn die Dinge in den alten Zustand gekommen wären, zurückgehen, indessen dies findet seine Erledigung durch den Umstand, dafe derselbe alle Verhandlungen übergeht, die dem Eingreifen des Konsuls vorausliegen. Die Auffassung der römischen Absichten ist auch bei Polyb dieselbe, wie bei Zonaras. Solange die Mamertiner in Angst vor Hiero waren, machten sie das Angebot, ihre Stadt den Römern auszuliefern; als sie aber in Sicherheit waren, konnte ihnen nicht damit gedient sein, nur den Herrn und die Besatzung zu wechseln. Wollten die Römer die Karthager aus Messana verdrängen, so mußten sie ihre Absichten als uneigennützige hinstellen. Dafs sie dies thaten,

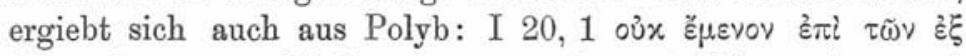

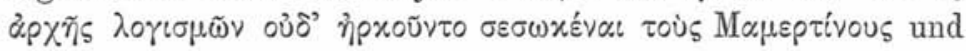
den gleichen Standpunkt vertritt auch Diodor, wenn er Hiero

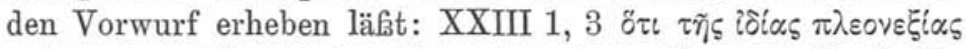

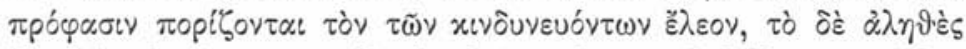

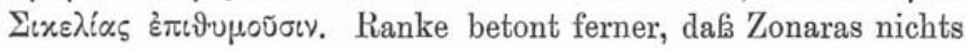
von den bei Polyb auftretenden Parteien der Mamertiner wisse, deren eine die Römer herbeizurufen wünsche, während die andere an die Karthager sich wende, indessen die wirklichen Ereignisse, die Furcht der Römer vor dem Eingreifen der Karthager und die Aufnahme dieser in Messana setzen doch eine den Karthagern zugethane Stimmung voraus, und es mochten in Wirklichkeit viele Mamertiner Bedenken hegen, die mit Hiero verbündeten Römer um Hilfe zu bitten, die vor wenigen Jahren erst mit solcher Strenge gegen ihre Stammesgenossen in Rhegiom eingeschritten waren. Weder bei Polyb, noch bei Zonaras haben wir es mit primären Berichten zu thun, aus der weniger scharfen Hervorhebung einzelner Züge darf man bei beiden nicht zu viel folgern wollen. Wenn Gort-

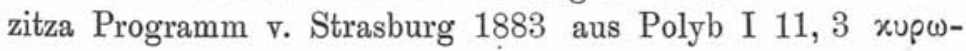




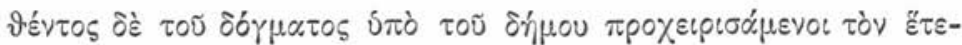

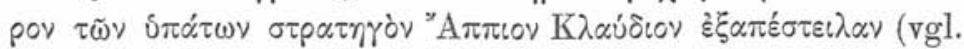

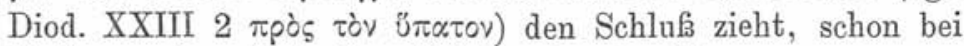
Philinos seien die beiden Claudier in eine Person zusammengezogen, so trifft diese Folgerung durchaus nicht zu. Diodor XXIII 1, 3 stellt den Sachverhalt ganz der Wirklichkeit entsprechend dar, dafs die Römer auf die Nachricht von der Belagerung Messanas durch Hiero und die Karthager den Konsul

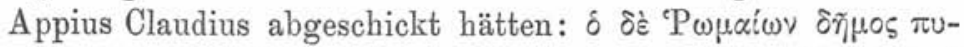

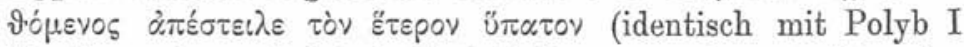

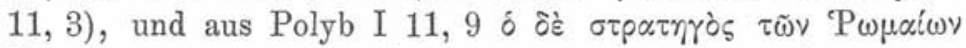

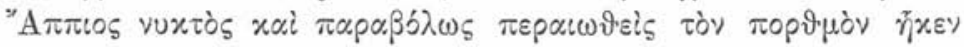

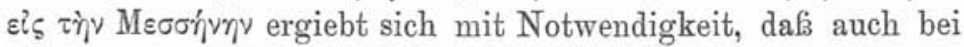
ihm verschiedene Persönlichkeiten gemeint sind, daf wir es also in $\S 3$ mit einer Flüchtigkeit des Schriftstellers zu thun haben. Die Berichte Polỷbs und des Zonaras schliefen also einander nicht aus, sondern ergänzen sich, sie beruhen auf der gleichen Quelle, die sich auch in einer Reihe gemeinsamer

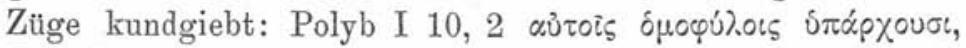

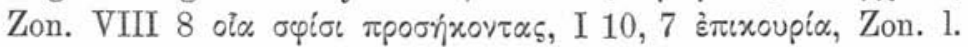

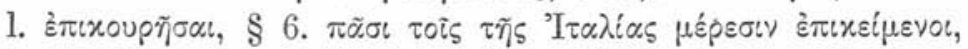

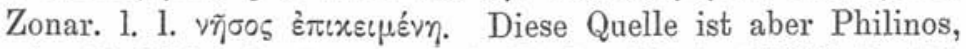
wie die Uebereinstimmung mit Diodor lehrt: XXIII 2 oủò vi

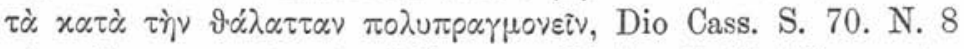

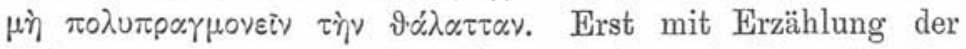
Kriegsoperationen giebt Dio (Zonaras) diese Quelle auf, während Polyb ihr noch weiter folgt.

Das Jahr 259 ist von Polyb I 24, 8 ganz übergangen:

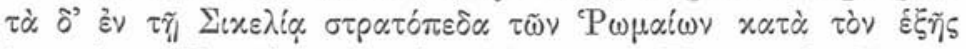

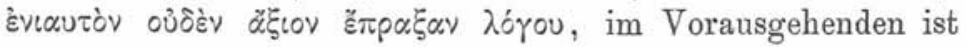
aber mit der Erzählung von Hannibals Tod bereits in das Jahr 258 übergegriffen (Zonar. VIII 12, Liv. per. 17).

Die Jahre 255 und 254.

Nach der Niederlage des Regulus schicken die Römer mit

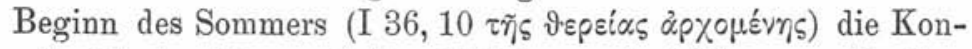
suln M. Aemilius und Ser. Fulvius nach Afrika, um die dem Untergange entronnenen Trümmer des Heeres nach Italien 
zurückzuführen. Dieselben erringen den Sieg am Hermäischen Vorgebirge, erleiden aber auf der Rückfahrt Schiffbruch bei

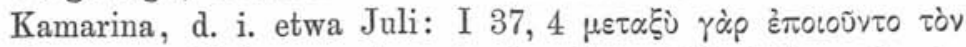

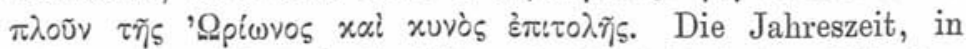
welcher dies Unglück die Römer traf, steht fest, nicht aber das Jahr, welchem dasselbe zuzuweisen ist. Fränkel Stud. 1, 14 behauptete, daf der von Polybius erwähnte Sommer unmöglich der Sommer des Jahres 255 sein könne, und darin stimmte Seipt quaest. chronol. S. 38 ihm bei. Gegen beide wandte sich Soltau Röm. Chronologie S. 208 und suchte nachzuweisen, dafs man an 355 als dem Jahre des Schiffbruchs festzuhalten habe, und ihm schlof sich Meltzer II S. 573 an: „Für die zeitlichen Ansätze braucht jetzt nur auf die wohlbegründete Darlegung von W. Soltau Röm. Chronol. S. 208 verwiesen zu werden. Es ist doch wunderbar, dak es eines besonderen Eintretens dafür bedarf, daf Zeitangaben, wie diejenige bei Polyb I 37, 4, die Ausgangspunkte unserer chronologischen Ansetzungen sein und bleiben müssen. " Eine Nachprüfung der Ansätze hat mich indessen von der Richtigkeit der Fränkelschen Aufstellungen überzeugt: Der Sommer, in welchen Polybius den Schiffbruch setzt, kann nur der Sommer des Jahres 254 sein. Die Zeitangabe bei Polyb I 37, 4 bleibt dabei Ausgangspunkt unserer chronologischen Ansetzung, nur muf dieselbe richtig verstanden werden. Als Regulus seine Friedensverhandlungen mit den Karthagern anknüpfte, hegte er Besorgnis, Karthago nicht erobern zu können, sondern den Ruhm der Beendigung des Kriegs seinem Nachfolger überlassen zu müssen (Polyb I 31, 4). Damals war Regulus noch Konsul (Diod. XXIII 12, $1 \delta$ ü $\pi \alpha \tau \varsigma \varsigma)$, aber das Ende seines Amtsjahres war nahe herangerückt. Er führte über dies hinaus den Oberbefehl d. i. über Mai 255: Liv. per. 18 cum successor ei a senatu prospere bellum gerenti non mitteretur, id ipsum per literas ad senatum missas questus est etcet. vgl. Val. Max. IV 4, 6, Dio Cass. 43, 20, Front. IV 3, 3, Senec. ad Helv. 12, auctor de vir. ill. 40. Seine Niederlage fiel bereits

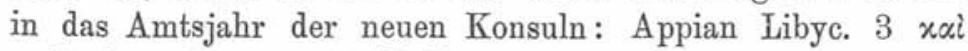

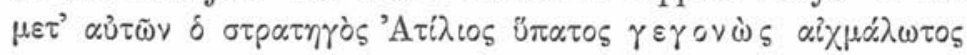

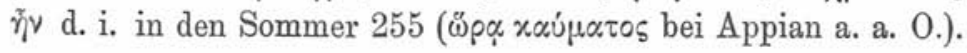


Dies Jahr wird auch Liv. XXVIII 43, 17 ff. vorausgesetzt: neque recordatur ... res egregias primo anno gessisse, $\S 18$ si nuper et non annis ante quadraginta - muf heifen quinquaginta - ista clades accepta foret (d. i. im Juli 205). Gehört aber die Niederlage bereits dem Jahre 255 an, dann kann der Schiffbruch nicht mehr im Juli 255 erfolgt sein. Sobald die Römer von der Vernichtung ihres Heeres Kunde erhielten, begannen sie sofort mit der Ausrüstung einer Flotte, die Karthager aber wandten sich der Belagerung von Clupea zu, hatten jedoch keinen Erfolg und standen deshalb von derselben wieder ab. Die Römer segelten darauf nach Afrika, gewannen den Sieg beim Hermäischen Vorgebirge, brachten den eingeschlossenen Rest des afrikanischen Heeres auf die Schiffe und kehrten dann nach Sizilien zurück, wo sie der genannte Schlag traf. Alles dieses läfat sich nicht in den Raum von wenigen Wochen zusammendrängen; denn mit Ende Mai - dies ist der Ausgangspunkt Soltaus - können die neuen Konsuln nicht abgesegelt sein, weil man damals in Rom von der Niederlage noch gar nichts wissen konnte. Daraus

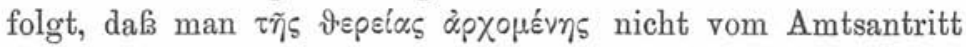
der neuen Konsuln verstehen darf, M. Aemilius und Ser. Fulvius sind erst 254 aus Italien abgefahren, nicht zur Zeit, da ihr Konsulat begann, sondern da es bereits bald zu Ende ging. Mit diesem Ansatz lassen sich auch die Angaben bei Diodor und Orosius in Einklang bringen. Wenn der erstere XXIII

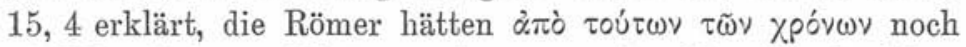
15 Jahre Krieg geführt, so nimmt er, obwohl er von den Verlusten der Römer zur See spricht, als Ausgangspunkt nicht die Katastrophe von Kamarina, sondern die Verhandlungen des Regulus mit den Karthagern. Denn das Thema, das er erörtert, bildet der Nachweis, daf des Regulus übertriebene Forderungen einen vollständigen Umschwung der Verhältnisse herbeiführten und den Karthagern den Sieg, ihm selbst und seinem Volke aber schwere Niederlage und unersetzliche Verluste brachten. Orosius IV 9, 3 weist die Niederlage des Regulus dem 10. Kriegsjahr zu: decimo demum anno Punici belli nobilem triumphum Carthaginiensibus praebuit, im 3. Jahre darnach erfolgte die Ausfahrt des Ser. Caepio und Sempronius 
Blaesus: IV 9, 10 tertio anno d. i. 253/2, da Orosius das Konsulat des Cn. Cornelius Scipio und A. Atilius (254/3) übergeht. Nach den Triumphalfasten haben Ser. Fulvius und M. Aemilius am 22. resp. 23. Januar 253 triumphiert. Fränkel, der erklärt hatte, die Sieger seien zur Zeit des Siegs nicht Konsuln, sondern Prokonsuln gewesen, hält Soltau mit Recht entgegen: „Die Triumphaltafel sagt, daß3 Aemilius und Fulvius als Prokonsuln triumphierten, dafs sie als solche siegten, sagt sie nicht"; gleichwohl hätte Fränkel das Zeugnis der Triumphalfasten für seinen Ansatz geltend machen können. Wenn der Sieg am Hermäischen Vorgebirg dem Jahre 255 angehörte und die Konsuln des Jahres 254/3 gleich mit Be-

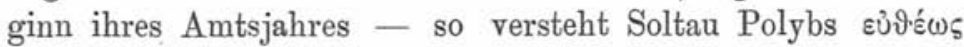
mit recht gewundener Erklärung und gänzlicher Nichtberück-

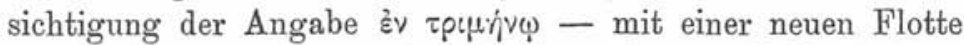
ausliefen, dann vermag niemand einzusehen, weshalb die Konsuln des Jahres 255/4 nach erfolgter Ablösung im Mai 254 noch $3 / 4$ Jahre mit der Feier ihres Triumphes warteten. Erfolgte aber das Unglück von Kamarina im Juli 254, dann

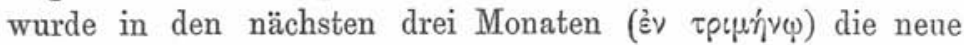
Flotte ausgerüstet, und die neuen Konsuln $\mathrm{Cn}$. Cornelius und A. Atilius liefen nach ihrer Fertigstellung im Herbste 254 aus, während Aemilius und Fulvius heimkehrten, um im Januar 253 ihren Triumph zu feiern. Die Konsuln des Jahres 254/3 erobern Panormos, die Konsuln des Jahres 253/2 segeln während des Sommers 253 (Polyb I 39, 1) nach Afrika, und 'die Römer verlieren auf der Rückfahrt zum 2. Male durch Sturm ihre Flotte. Mit Rücksicht auf Polyb I 39, 1 setzt Soltau ihre Ausfahrt in den Beginn des Amtsjahres, doch be-

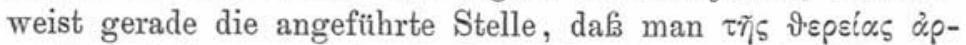

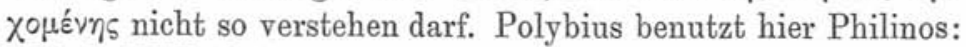

Diod. XXIiI 18, 2 है

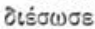

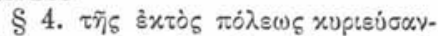

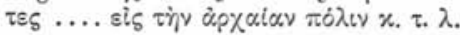

5. of ठ่̇ $\mu \varphi$ 入

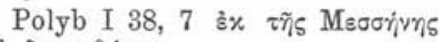

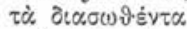

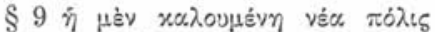

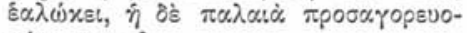

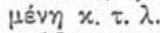

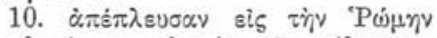

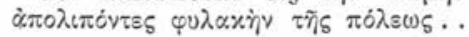

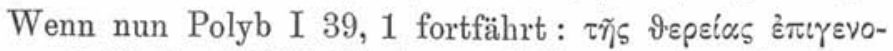

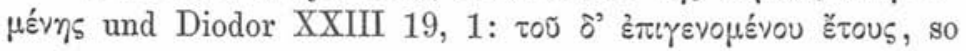


unterliegt es keinem Zweifel, daf ersterer seine Angabe aus Philinos entnommen hat, daf er also den Beginn eines neuen Kriegsjahres, nicht eines römischen Konsulatsjahres verzeichnet.

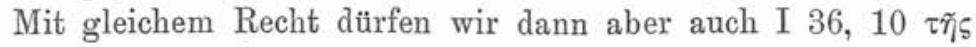

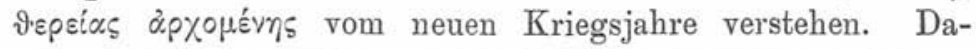
mit wird das von Soltau statuierte Gesetz hinfällig, daf Sommersanfang von Polyb stets vom Frühjahrsanfange bestimmt unterschieden werde und um den Plejadenaufgang (Mitte Mai) falle. In dem Abschnitt über den 1. punischen Krieg erwähnt Polyb niemals den Frühjahrsanfang, sondern spricht, wohl nach Philinos, bei Beginn der Operationen nur von Sommersanfang: I 25,$7 ; 36,10 ; 39,1 ; 59,8$. Ob Scipio direkt nach Rom zurückgekehrt ist, ist zweifelhaft, da er erst im März 252 triumphiert; Diod. XXIII 18, 5 scheint dafür zu sprechen, daßs er noch als Prokonsul den Landkrieg auf Sizilien weiter führte, während die neuen Konsuln nach Afrika fuhren.

Schlacht bei Panormos.

Die Jahreszeit, in welcher die Schlacht bei Panormos

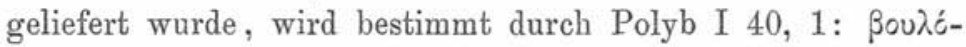

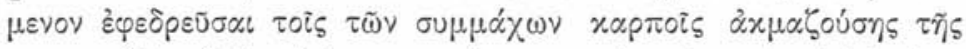

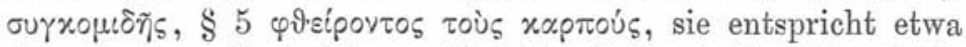
dem heutigen Juni (Nissen, Ital. Landeskunde S. 400). Während Mommsen aber den Sieg dem Jahre 251 zuweist, hat nach Thne Cäcilius Metellus als Prokonsul im 15. Kriegsjahre (250) über Hasdrubal gesiegt, und ähnlich spricht sich Soltau aus: „Auf die Kunde von diesem Siege schickte der Senat die neuen Konsuln mit einer vorher ausgerüsteten Flotte ab (Polyb I 39, 15). Als diese in Sizilien angekommen war, begab sich der siegreiche Konsul nach Rom, wo er VII id. Sept. triumphierte." Auch bei der zeitlichen Bestimmung der Schlacht von Panormos schliebt Meltzer sich an Soltau an (S. 577). Für das Jahr 250 scheinen folgende Momente zu sprechen: 1) erwähnt Polyb I 39, 15 vor der Schlacht bereits die Konsuln des Jahres 250, 2) ist nach seiner und des Zonaras Darstellung der eine Konsul schon nach Italien (Rom) zurückgekehrt. Was den ersten Punkt betrifft, so scheint es, als ob zur Zeit des Sieges die neuen Konsuln ihr Amt schon 


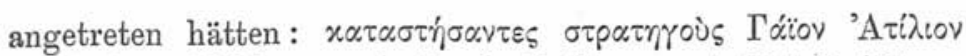

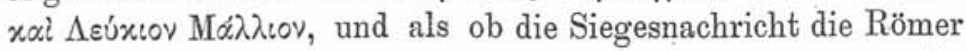
erst recht bestimmt hätte, auch zur See wieder gegen die

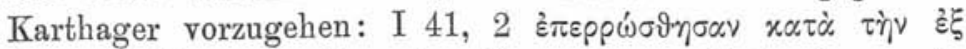

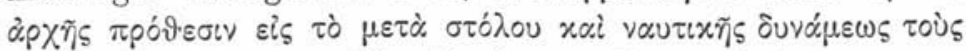

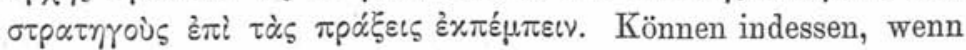
Metellus im Juni 250 siegte, die neuen Konsuln sofort mit einer Flotte ausgefahren sein, deren Stärke Polybius (I 41, 3) und Orosius (IV 10,2) auf 200 Kriegsschiffe berechnen, Diodor (XXIV 1, 1) auf 240 Kriegsschiffe und 60 leichte Schiffe? Noch I 39, 8 hatten die Römer nur 60 Schiffe in Bereitschaft (Eutrop II 23; Oros. IV 9, 12), um dem Heer Lebensmittel zuzuführen; zu diesen wurden nach I 39,15 noch 50 weitere gebaut. Das ergiebt 110 Schiffe, ein sofortiges Auslaufen mit 200 Schiffen ist somit unmöglich. Die Darstellung Polybs ist sehr gekürzt und darum auch stellenweise ungenau: Nachdem er I 38, 5 die Konsuln des Jahres 254, I 39, 1 die von 253 erwähnt hat, macht er I 39, 5 die des Jahres 251 L. Cäcilius und G. Furius namhaft, um in I 39, 15 zu den Konsuln von 250 tiberzugehen und in I 40 den Sieg des Cäcilius Metellus zu erzählen. Das Jahr 252 wird also ganz mit Stillschweigen übergangen. Unrichtig ist die Mitteilung aus dem Jahre 251

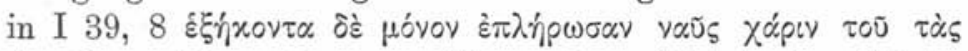

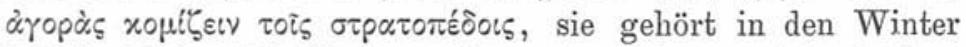
253/2: Eutrop II 23 decrevit senatus, ut sexaginta tantum naves ad praesidium Italiae salvae essent, Oros. IV 9, 12, Zonar. VIII 14. Die ganze Partie I 39, 7-15 ist nicht dazu bestimmt, die Erzählung weiterzuführen, sondern enthält zusammenfassende Erörterungen über die Mut- und Ratlosigkeit der Römer in den auf die Niederlage in Afrika und auf die Unglücksfälle zur See folgenden Jahren, wie sie ähnlich auch Diodor anstellt:

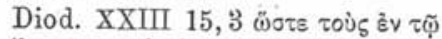

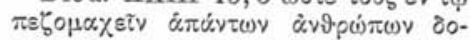

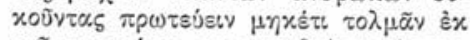

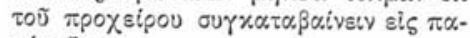
$\rho \dot{\alpha} \tau \alpha \xi$ เv.

Polybius benützt Fabius und Philinos, aus dem ersteren stammt der Bericht über den zweiten Schiffbruch (vgl. I 39, 2 Philologus LX (N. F. XIV), 1.

Polyb. I 39, 12 oiี

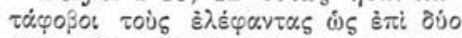

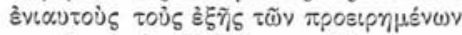

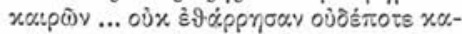

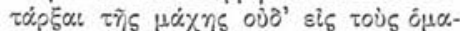

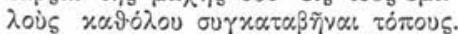




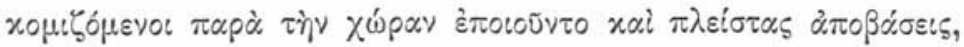

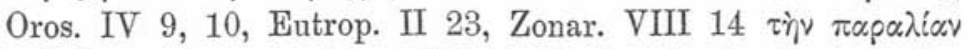

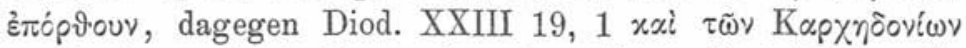

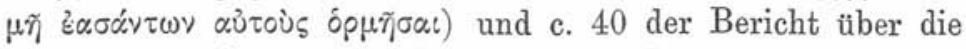
Schlacht von Panormos. Dazwischen stehen die aus Philinos geschöpften allgemeinen Erörterungen, in denen Polyb auch auf die Ereignisse des übergangenen Jahres 252 (I 39, 13 vgl. mit Diod. XXIII 20) eingeht und bereits das Jahr 250 berührt, weil in diesem Jahr die Römer zum ersten Male wieder mit der Flotte sich aufs Meer hinauswagen. So läßst ihn die Benützung verschiedener Quellen den Ereignissen vorgreifen und das Jahr 250 in den Kreis seiner Betrachtungen ziehen, bevor er die Geschichte des Jahres 251 erzählt hat. Für Ablauf des Konsulatsjahres 251/50, also für das Jahr 250 könnte auch der Umstand sprechen, daßs der eine Konsul mit der Hälfte des Heeres bereits nach Italien zurückgegangen ist, indessen, da Polyb und Zonaras den Grund für diese Maß3nahme nicht angeben, folgt die Notwendigkeit dieser Annahme aus der gedachten Mitteilung noch nicht; es bliebe unverständlich, weshalb Furius vor der Ankunft der neuen Konsuln abzog und Cäcilius mit dem geschwächten Heere allein in der gefährdeten Stellung zurücklief. Wir müssen uns bescheiden, den Grund für diese auffallende Zurücknahme des Heeres nicht zu wissen. Für die Bestimmung der Zeit des Sieges kommt auch Oros. IV 10, 1 in Betracht: ad quam rem Atilium Regulum .. quem iam per quinque annos captivum detinebant, mittendum putaverunt. War Regulus schon 5 Jahre in Kriegsgefangenschaft, dann fällt seine Gesandtschaft ins Jahr 250. Dieser ging aber der Sieg von Panormos voraus. Zonaras spricht dabei von der Anwesenheit der

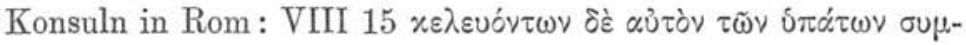
$\mu \varepsilon \tau \alpha \sigma \chi \varepsilon i \nu$ $\chi . \tau$. $\lambda$. Siegte Cäcilius erst im Sommer 250, dann ist nicht denkbar, daf die Konsuln zwischen dem Siege, für den Cäcilius im August triumphierte, und ihrer Ausfahrt (Polyb I 41) die Verhandlungen mit Regulus in Rom führten; Zonaras wird vielmehr den Beginn des Amtsjahres 250/49 als den Zeitpunkt der Verhandlungen im Auge haben: war Regulus 255 in Gefangenschaft geraten und wurde er etwa Mai 
250 als Gesandter nach Rom geschickt, dann würde der Ausdruck per quinque annos scharf zutreffen. Der Sieg von $\mathrm{Pa}-$ normos müfte dann aber dem Sommer des vorausgehenden Jahres zugewiesen werden. Für das Jahr 251 sprechen aber auch andere Momente. So wird Cäcilius wiederholt ausdrücklich als Konsul, nicht als Prokonsul bezeichnet: Diod. XXIII 21

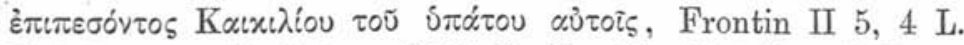
Metellus consul., Eutrop II 24 L. Caecilio Metello, C. Furio Pacilo coss., Oros. IV 9, 14 L. Caecilio Metello C. Furio Pacilo consulibus Hasdrubal novus Carthaginiensium dux imperator Lilybaeum venit ex Africa et continuo cum Metello consule apud Panormum pugnam conseruit, Zonar. VIII 14 of

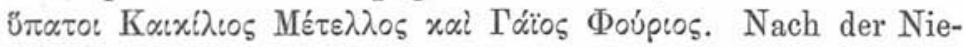
derlage des Regulus sollen, so berichtet Polyb, die Römer 2 Jahre lang nicht im offenen Felde zu erscheinen gewagt

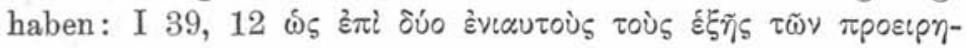

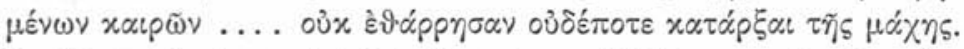
In dieser Fassung ist die Angabe unrichtig: wurde Regulus 255 v. Chr. besiegt, dann traten die Römer 3 Jahre lang (254. 253. 252) den Karthagern zu Lande nicht entgegen und fanden erst nach dem Siege von Panormos den Mut wieder, sich in einen Landkampf einzulassen. Weil Polyb das Jahr 252 übergeht, rechnet er nur 2 Jahre, wie er auch I 41, 3 das Jahr 250 aus dem gleichen Grunde als 14., statt als 15. Kriegsjahr rechnet. Möglich ist auch die Erklärung, daß3 Polybius die Zeit vom 2. Seesturme bis zum Siege von Panormos im Auge hat (Sommer 253 - Sommer 251); dann würde er den Ausgangspunkt unrichtig angeben, aber seine Rechnung würde stimmen. Diese Annahme verdient vielleicht deshalb den Vorzug, weil Polyb in dem aus Philinos entlehnten Abschnitte (I 39, 7-15) auf die Ereignisse des Jahres 252 Be-

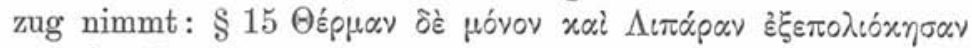
x. $\tau$. $\lambda$. Die Belagerung von Lilybaion berechnet Diodor auf

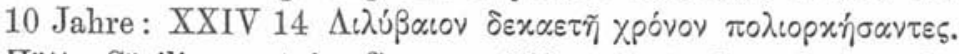
Hätte Cäcilius erst im Sommer 250 gesiegt, dann könnte die Belagerung erst im Herbst 250 begonnen haben, von einer zehnjährigen Dauer derselben könnte nicht die Rede sein, und alles, was Polyb I 41-49 (Diod. XXIV 1, 1-4) berichtet, 
würde nur den Winter 250/49 und das Frühjahr 249 umspannen. In das Jahr 251 setzt den Sieg des Cäcilius auch Plin. VIII 6 elephantos Italia primum vidit Pyrrhi regis bello .... anno urbis quadringentesimo septuagesimo secundo (281 v. Chr.): Roma autem in triumpho, septem annis ad superiorem numerum additis. Eadem plurimos anno quingentesimo secundo victoria L. Metelli pontificis in Sicilia de Poenis captos (vgl. XXXV 7, 5 anno ab urbe condita $\mathrm{CCCCXC}=263$, Sieg Messalas). Nach seinem Siege blieb Cäcilius in Sizilien, bis im Frühjahr 250 die neuen Konsuln dort eintrafen; der Marsch mit den erbeuteten Elephanten durch Italien nahm die Zeit bis Ende August, zu welchem Zeitpunkt er seinen Triumph in Rom feierte, in Anspruch.

Die J a hre $250-248$.

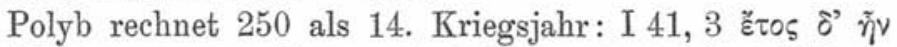

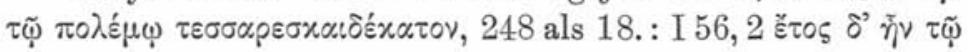

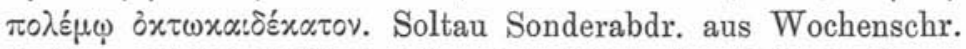
f. klass. Philol. 1888 S. 13 meint, Polyb, der I 63 die Dauer des Kriegs auf 24 Jahre berechne, setze sich dadurch, daf er 250 als 14. Kriegsjahr berechne, mit seiner Berechnung der Gesamtdauer in Widerspruch; der catonische Ansatz habe ihn veranlafit, die Ereignisse des Konsulatsjahres 249 unter 2 Jahre zu verteilen und so 248 als 18 . Kriegsjahr zu behandeln. Polyb habe, so behauptet er, da er den Anfang des Kriegs in Ol. 129, 1 setze und das 15. Kriegsjahr als 14 . behandle, nur 23 Kriegsjahre rechnen dürfen. Man muk also Polyb die bewußste Absicht zuschreiben, seinen ursprünglichen Ansatz mit der widersprechenden Berechnung seiner Quellen in Einklang $\mathrm{zu}$ bringen. Ich kann dieser Ansicht Soltaus nicht zustimmen.

Polyb giebt nur einen kurzen Abrif der Geschichte des ersten punischen Kriegs, seine Kürze verleitet ihn wiederholt zu Irrtümern, aber dieselben sind zu leicht erkennbar, als daf es gestattet wäre, künstliche Deutungen derselben anzustellen, wie dies Soltau thut. Nach Olympiadenjahren bestimmte er,

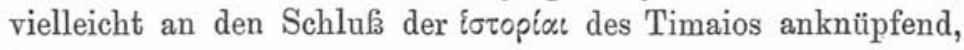
nur den Anfang des Kriegs, im weiteren Verlaufe desselben kennt er nur Kriegsjahre: I 16, 1; 17, 6; 20, 4; 21, 4 u.

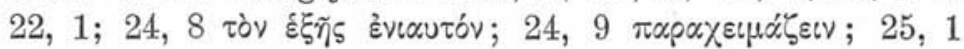




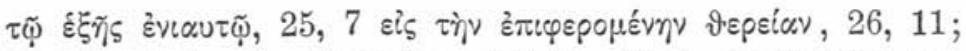

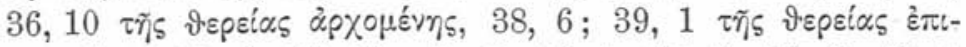

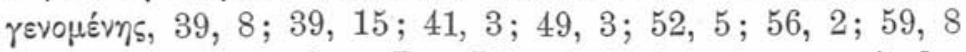

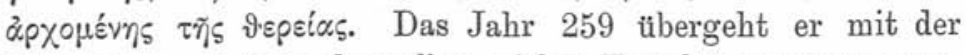
Bemerkung, dak in demselben nichts Erwähnenwertes vorgefallen sei; schlimmer ist, dafs er 252 ganz unberücksichtigt gelassen und dies nicht selbst bemerkt hat. Bis 39, 1 hat er richtig 12 Jahre gerechnet, 252 ist das 13. Jahr; da aber die Konsuln dieses Jahres übergangen sind, so wird 251 als 13. und 250 als 14. Jahr gerechnet. Diese Erklärung, welche Seipt gegeben hat, ist so natürlich und durch die Erzählung Polybs so sehr an die Hand gegeben, daß es unnötige Schwierigkeiten sich schaffen heißst, wenn man davon abgeht und andere Deutungen in Erwägung zieht. Ebensowenig kann I 56, 2 von einer Absicht Polybs die Rede sein, sondern nur von einem Irrtum. Soltau bemerkt dazu: "Wie ihm 513 das 24., so war ihm 507 das 18. Jahr. Wenn er 504 das 14. nennt, so wäre schon hiernach anzunehmen, dafs er die zwischen 504 und 507 liegenden 3 Amtsjahre auf 4 Kalenderjahre verteilt habe, und wirklich macht Polyb I 52 den Versuch, die Ereignisse von 505 auf 2 Jahre zu verteilen. Nach der Niederlage des einen Konsuls von 505, des P. Claudius Pulcher

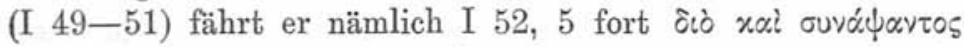

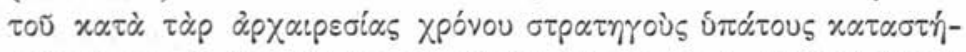

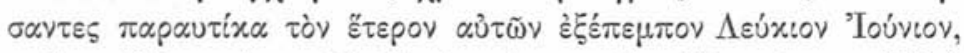
und es folgen dann die Thaten des zweiten Konsuls von 505." Den Anlafs zu diesem handgreiflichen Irrtum findet Soltau darin, daf Polyb eine römische Quelle benutzte, die nach Kriegsjahren erzählte und die Erzählung des neuen Kriegsjahres 248 v. Chr. mit den Ereignissen zu Ende des Amtsjahres 505 begann. Diese Vermutung könnte annehmbar erscheinen, um so mehr, als Polybius hier wirklich einen Wechsel seiner Quelle vornimmt. Die Quelle, die er für die Thaten des Junius benutzt, ist freilich keine römische, sondern Polyb folgt hier dem Agrigentiner Philinos. Die Belagerung von Lilybaion (250 v. Chr.) erzählt er nach Philinos, wenn er auch von Irrtümern nicht frei ist und den Zahlenangaben seines Gewährsmannes miftraut. In diesem Abschnitte hält 
er sich wieder nicht an das behandelte Jahr, sondern greift

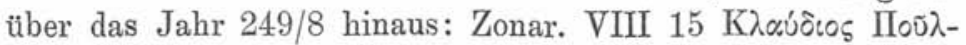

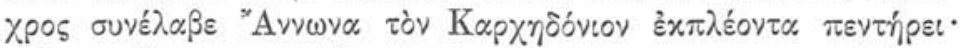

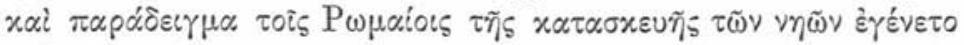

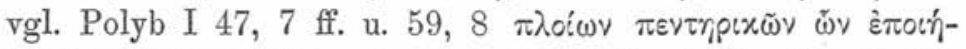

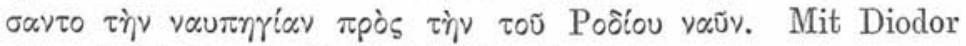
stimmt Polyb zum Teil wörtlich überein:

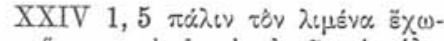

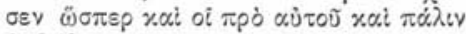

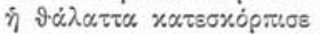

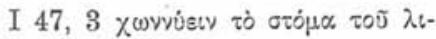

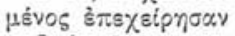

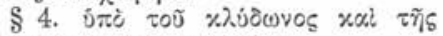

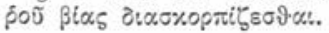

Der Bericht über die Schlacht von Drepana dagegen stammt wahrscheinlich aus Fabius, wenigstens sind nach diesem die Verluste mitgeteilt (Eutrop II 26, Oros. IV 10, 3). Der Untergang der Flotte des Junius wird dagegen wieder nach Philinos erzählt, nur miftraut Polyb den Zahlenangaben desselben und geht seinen eigenen Weg. So hatte nach Polyb I 53, 2 Karthalo 70 Schiffe und erhielt zu denselben von Adherbal noch 30 andere (I 53,2), während er nach Diod. XXIV 1, 7 mit 120 Schiffen in See ging. Hier wäre ein Fehler der Ueberlieferung bei Polyb nicht ausgeschlossen, andererseits sind die Zahlen 30 und 70 bei Polyb durch Diod. XXIV 1, $7 \mu \varepsilon \tau \dot{\alpha}$

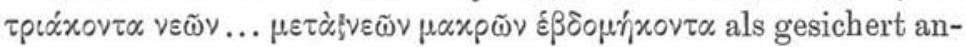
zusehen (so Meltzer S. 581). Anders steht es mit folgenden An-

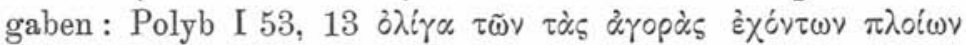

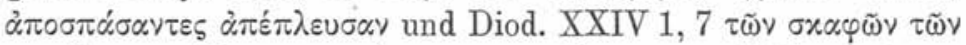

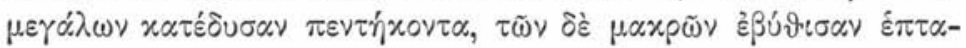

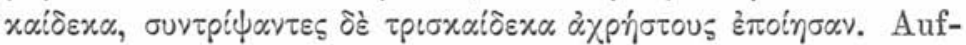
fallender Weise stimmt aber, wenn man die Diod. XXIV 1, 7 erwähnten Verluste nicht mitrechnet, die Gesamtzahl der Schiffe des Junius bei beiden Schriftstellen wieder überein: I 52, 6 है $\chi \omega \nu$

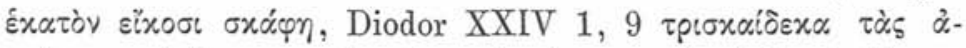

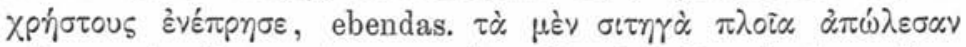

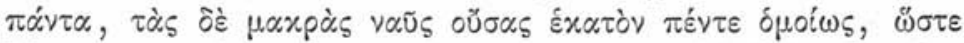

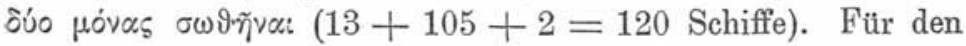
gemeinsamen Ursprung sprechen unbedingt folgende Stellen:

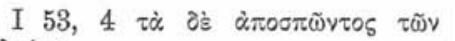
$\pi \lambda \circ i^{i} \omega v$

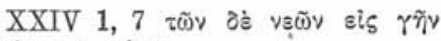

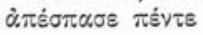


8. $\pi p \circ \sigma \alpha \gamma \gamma \varepsilon t \lambda \dot{\alpha} v \tau \omega \nu \ldots \dot{\alpha} v \alpha \chi \vartheta \varepsilon i \zeta$

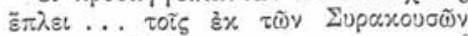
$\pi$ тро $\pi \varepsilon \tau \tau \alpha \lambda \mu \varepsilon \dot{v} 0: \varsigma$

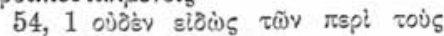

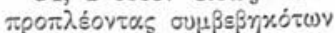

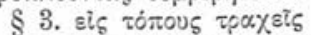

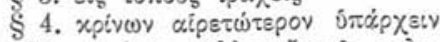

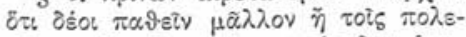

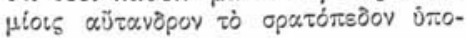
Xsiptov $\pi 0$ iñoct

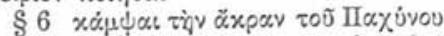

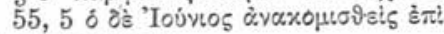

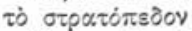

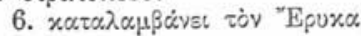

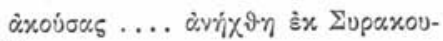
ฮิ๊ท

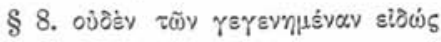

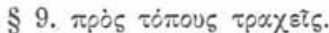

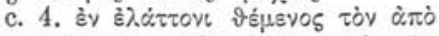

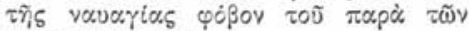
$\pi 0 \lambda . \varepsilon \mu i \omega v$ ழ̣óßov

§ 9. жช்

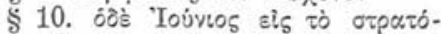
$\pi \varepsilon \partial 0 \nu$ ทेंगे

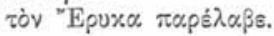

Von der Gefangennahme des Junius, die Zonaras erzählt, weißs weder Diodor noch Polyb etwas. So nehme auch ich nach c. 52 bei Polyb einen Quellenwechsel an, aber er wählt nicht eine römische, sondern eine griechische Quelle. Auch diese rechnete nach Kriegsjahren, aber unmöglich kann sie mit der Erzählung der Thaten des Junius ein neues Kriegsjahr begonnen haben, denn „es ist“, wie Meltzer richtig S. 330 ausführt, "ganz undenkbar, daß3 Junius bei der Ueberführung des groken Transports in das Lager von Lilybäum so verfahren wäre, wie es wirklich geschehen ist, wenn er wenigstens bei der Voraussendung der ersten Flottenabteilung bereits von der Niederlage seines Kollegen unterrichtet gewesen wäre". P. Claudius und Junius sind ungefähr gleichzeitig, der eine vor Lilybaion, der andere in Syrakus eingetroffen, die Flotte des letzteren wurde etwa Mitte Juli durch den Sturm vernichtet. Mit gutem Grunde macht Meltzer S. 578 auch darauf aufmerksam, daßs diese Gleichzeitigkeit der erzählten Ereignisse auch aus dem Berichte Polybs sich noch erkennen lasse: „Eine Spur von dem wahren Sachverhalte hat sich aber auch bei Polybius selbst erhalten, indem er I. 53, 1 die Beute

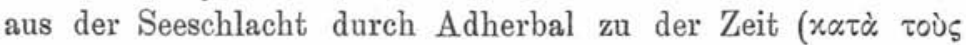

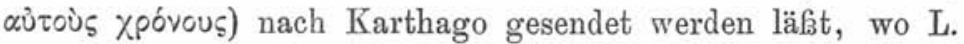
Junius bereits in Sizilien angelangt und für seine Aufgabe thätig ist." Auch sonst steht Soltaus Annahme mit den Quellen in Widerspruch. Nach der Niederlage von Drepana wurde Claudius Pulcher vom Senate zurückberufen und A. Atilius Calatinus zum Dictator ernannt: Liv. per. 19 A. Atilius Calatinus primus dictator extra Italiam exercitum duxit. Der 
Ernennung geht aber das Mifgeschick des L. Junius schon

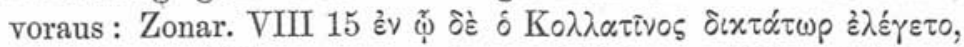

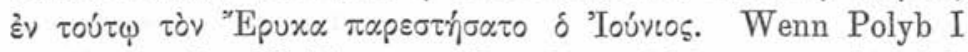
53, 5 von der Wahl neuer Konsuln spricht, so möchte ich annehmen, dab er die Konsulwahlen mit der Ernennung eines Dictators verwechselt und dafs sein Jahreswechsel diesem Irrtum seine Entstehung verdankt. So kommt er dazu, I 56, 2 das Jahr 248 nicht als 17., sondern als 18. Kriegsjahr zu bezeichnen. Trifft diese Annahme das Richtige, dann gehört das erste Auftreten des Hamilkar Barkas nicht ins 18., sondern ins 17. Jahr d. i. in 248. Dies bestätigt Zonaras VIII 16

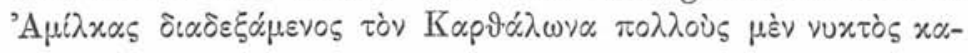

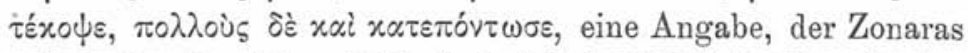
sofort den im Jahre 248 (vgl. Diod. XXIII 4, 1) erfolgten Abschluf des ewigen Bündnisses zwischen Hiero und den Römern folgen läßt. Die Verheerung der italischen Küste seitens der Karthager, deren Oros. IV 10, 4 (anno consequenti d. i. 248) gedenkt, ist keine andere, als die auch von Polyb I 56, 3 dem Hamikar zugeschriebene. Hat sich Polyb in I 56, 2 geirrt,

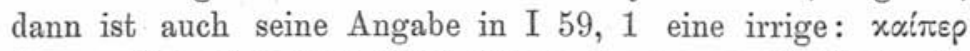

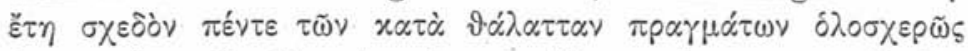

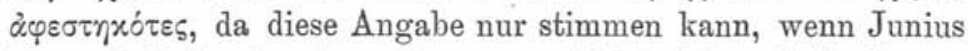
Flotte 248 durch einen Sturm vernichtet ist und die Römer 247. 246. 245. 244. 243 vom Meere sich fernhielten. Sie entsagten aber schon 249 dem Seekriege und verzichteten 6 Jahre lang (248-43) auf die Ausrüstung einer Flotte: Zonar. VIII 16

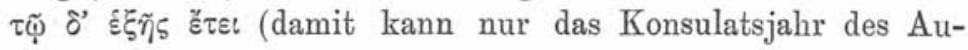
relius Gaius und Servilius Publius gemeint sein vgl. VIII 16

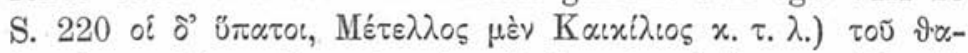

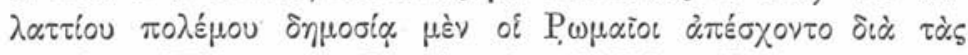

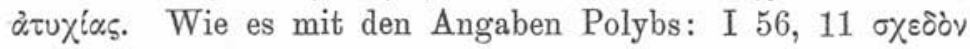

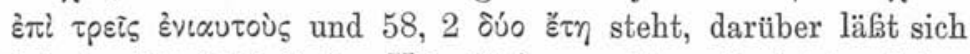
bei der Dürftigkeit der Ueberlieferung über die letzten Jahre nichts Bestimmtes ermitteln, wahrscheinlich sind sie aber richtig. Ueber das Jahr 247 haben wir noch den Bericht des

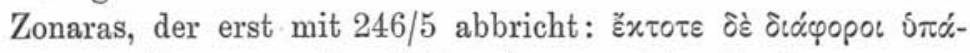
$\tau \varepsilon \cup \sigma \alpha \nu$. Da er von den Unternehmungen der Karthager gegen die italische Küste spricht, aber über Hamilkars Aufenthalt 
in Eirkte schweigt, so fällt die Besetzung dieser Feste erst ins Jahr 246/5, die von Eryx in das Jahr 243/2, wozu stimmt, daf3 Diod. XXIV 9, 2 bei den Kämpfen um Eryx den Konsul Fondanius (243/2) erwähnt. Auf Eryx blieb Hamilkar die

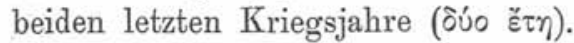

Die Schlacht bei den ägatischen Inseln.

Nach Eutrop II 27 wurde sie am 10. März 241 geliefert: pugnatum est VI idus Martias. Während Meltzer II S. 585 an diesem Datum festhält: „Für die Verlegung dieser Schlacht ist auch auffälligerweise wieder Ranke Weltgesch. 2, 1 S. 187 eingetreten ", hegt Soltan (S. 210) doch wenigstens Bedenken gegen Eutrops Ueberlieferung: "Nur das Datum der Schlacht bei den ägatischen Inseln VI idus Martias, 513 macht Schwierigkeit. Man sollte nach Polyb I 60 erwarten, daf Lutatius Anfang Sommer 242 v. Chr. ausgelaufen und inzwischen zwar Drepana belagert, aber, wie es wenigstens nach Polyb scheint, nicht überwintert habe. Bei der Kürze des Polybianischen Berichts ist nicht $\mathrm{zu}$ entscheiden, ob Polybius die Winterquartiere übergangen hat oder ob das Datum Eutrops falsch ist." Erstere Annahme hält Soltau allerdings mit Mommsen für das Wahrscheinlichere, und auch Neumann (S. 154) läßst Eutrops Datum als richtig gelten. Bestätigung scheint dasselbe durch Zonaras VIII 17 zu erhalten, wenn er berichtet: "Hanno floh nach der Schlacht sofort nach Karthago; die Karthager kreuzigten ihn, schickten aber zwecks Unterhandlungen über den Frieden Gesandte an

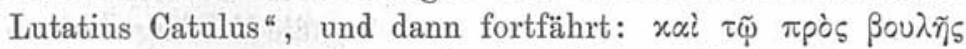

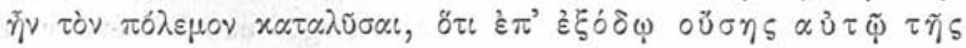

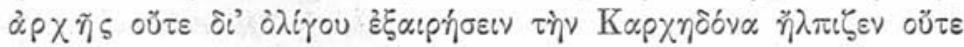

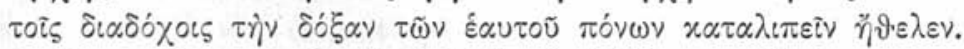
Andererseits kann der Schluf des Amtsjahres nicht in so unmittelbarer Nähe gewesen sein, sonst könnte Lutatius eine Belagerung Karthagos nicht mehr in Erwägung ziehen. Die Erzählung Polybs scheint aber mit dem Datum Eutrops sich nicht in Einklang bringen zu lassen. Die Römer hatten in ihrer Kriegführung wieder einen Systemwechsel eintreten lassen und sich zum Bau einer neuen Flotte entschlossen, die mit

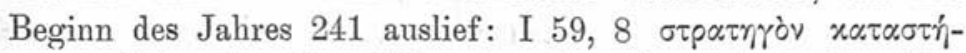

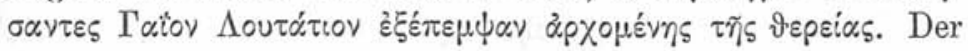


römische Feldherr richtete seinen Angriff zunächst auf Drepana und hätte die Festung genommen, wenn er nicht während der Belagerung verwundet worden wäre (Zonar. VIII 17; Oros. IV 10, 5 transfixo femore). An dieser Wunde litt er noch während der Schlacht bei den ägatischen Inseln: Eutrop. II 27, Val. Max. II 8, 2 consulem ex pugna claudum in lectica iacuisse; zwischen dem Kampfe vor Drepana und der Seeschlacht darf daher kein allzulanger Zwischenraum angenommen werden. Sobald die Karthager das Auslaufen der neugebauten römischen Flotte erfuhren, setzten sie ihre Flotte sofort in stand

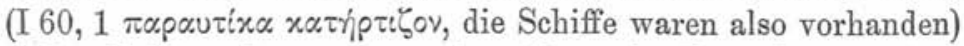
und schickten sie aus, um dem Heere in Eryx Lebensmittel zuzuführen. Wäre dies erst im Frühjahr 241 der Fall gewesen, dann hätten die Karthager etwa ${ }^{3} / 4$ Jahr verstreichen lassen, ohne das Heer Hamilkars mit Proviant zu versorgen; dies aber war, nachdem ihm von der römischen Flotte alle Zufuhr abgeschnitten war, nach Polyb I 58, 3 auf die Lebensmittel angewiesen, die ihm-von Karthago aus zugeführt wurden. Das Auslaufen der karthagischen Flotte muf demnach bald nach der Ausfahrt der römischen Flotte stattgefunden haben. Die karthagische Flotte erreichte indessen ihr Ziel nicht, sondern wurde von den Römern angegriffen und geschlagen. So die Darstellung Polybs; nach ihr würde kein Mensch auf den März 241 als Zeit der Schlacht kommen können, sondern würde dieselbe dem Jahre 242 zuweisen. Der Friedensschluf folgte nicht sofort, sondern die Karthager waren zunächst noch zur Fortsetzung des Krieges entschlossen und

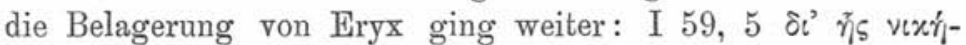

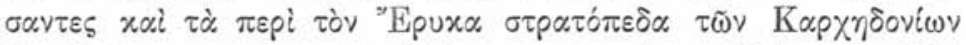

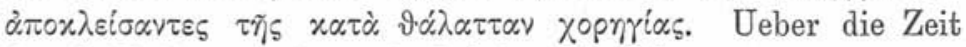
der Schlacht spricht sich Polyb auch II 43, 6 aus: $\tau \alpha \tilde{\tau} \tau \alpha$

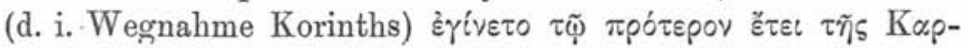

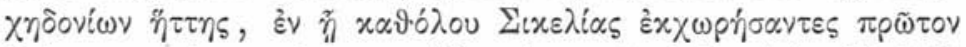

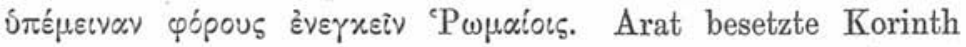

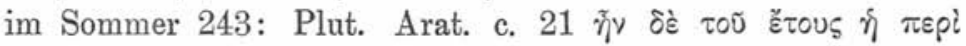

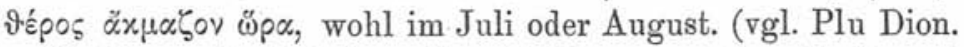
c. 23 v'śpous àxún d. i. nach c. 24 kurz vor dem 9. August

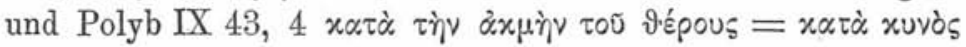




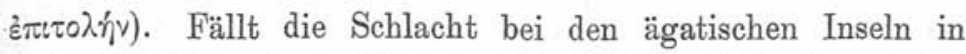
den März 241, dann beträgt der zeitliche Abstand zwischen ihr und der Besetzung Korinths $1 \mathrm{Jahr}$ und 7 Monate. Um diese Ungenauigkeit der Angabe Polybs zu beseitigen, setzte man bei seiner Berechnung Olympiadenjahre (0l. 134, $2=$ Korinths Befreiung, Ol. 134, 3 = Schlacht bei den ägatischen Inseln) oder achäisches Strategenjahr (Mai 243 - Mai 242 und Mai 242 - Mai 241) voraus: Droysen III 1 S. 416 A. 1 „Polybs Ausdruck ist fast völlig scharf, wenn Korinths Befreiung noch um den 1 Hekatombaion Ol. 143, 2 im hohen Sommer 243 lag." So rechnet aber Polyb in II 43 nicht. Die Befreiung Sikyons erfolgte am 5. Daisios d. i. im Frühjahr 251 (Plut. Arat c. 53, Droysen $\mathrm{III}^{2}$ S. 341 A. 1), im Olympiadenjahr 132, 1. Im 8. Jahre darnach entrif Arat den Makedoniern Korinth (II 43,4). Hätte er Olympiadenjahre zu grunde gelegt, dann fiele letzteres in das Olympiadenjahr $134,1=244 / 3$. Angenommen die àxpì v'śpous fiele mit dem Ende des Jahres 244/3 zusammen, dann würde die Schlacht bei den ägatischen Inseln doch ins zweite Olympiadenjahr nach der Wegnahme Korinths fallen müssen. Die Sache steht daher so, dak Polyb keine bestimmte Jahresform im Auge hat, sondern den Zeitabstand nach Jahreslängen begrenzt: 251 befreit Arat Sikyon, 8 Jahre darnach d. i. 243 besetzt er Korinth. Dann mufs aber das der Besetzung Korinths folgende Jahr das Jahr 242, nicht 241 sein und Polyb setzt auch II 43, 4 die Schlacht bei den ägatischen Inseln ins Jahr 242, nicht ins Jahr 241.

Dies Resultat geben auch andere Erwägungen an die Hand, die an die Ankunft Hamilkars in Spanien anknüpfen. Die Ermordung Hasdrubals erfolgte im Jahr 221 (Polyb III

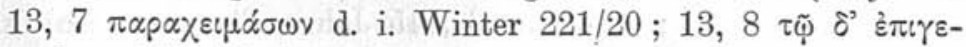

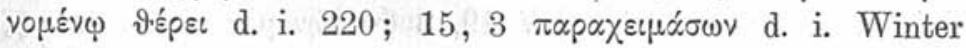

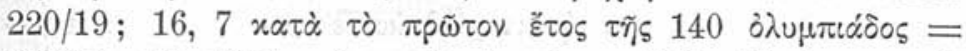

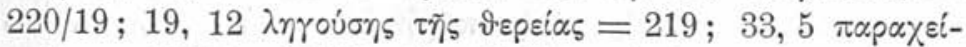
$\mu \alpha \zeta \omega \nu=$ Winter 219/8; Cornel Hann. 3, 2 proximo triennio omnes gentes Hispaniae bello subegit). Er führte 8 Jahre lang den Oberbefehl (Polyb II 36, 1, Liv. XXI 2, 3; Diod.

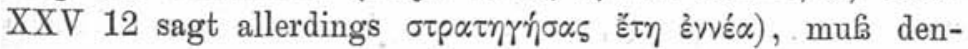


selben also 229 angetreten haben; Polyb III 10, $7 \tau \varepsilon \tau \varepsilon \lambda \varepsilon u-$

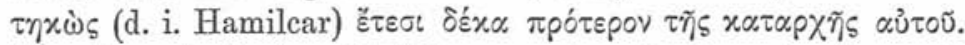
Hamilkar starb also 10 Jahre vor dem Beginne des 2. punischen Kriegs oder vielmehr vor dem Angriff auf Sagunt, den Polyb III 6, 3 als Beginn des 2 punischen Kriegs bezeichnet. Denselben Zeitpunkt hat er III 2, 1 und III 13, 1 im Auge: Hasdrubal begann seinen Oberbefehl in derselben Zeit ( $\alpha \propto \tau \grave{\alpha}$

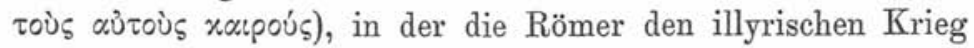
eröffneten (Konsulat des L. Postumius und Cn. Fulvius bei Polyb II 11, 1 u. Eutrop III 4; Polyb II 12, $2 \pi \alpha \rho \varepsilon \chi \varepsilon i \mu \alpha \zeta \varepsilon$,

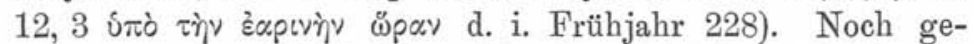
nauer bestimmt die Zeit von Hamilkars Tod Diod. XXV 10, 3 sic $\pi \alpha \rho \alpha \chi \varepsilon t \mu \alpha \sigma i \alpha \nu$ d. i. Winter 329/8. Dieser bestimmten Mitteilung gegenüber kommt nicht in Betracht: Cassiod. chron. a. 524 M. Aemilius et M. Junius, his consulibus Hamilcar Hannibalis pater in Hispania Romanis bellum parans occisus est (vgl. Zon. VIII 19 und Oros. IV 13, 1). Hamilkar, der Winter 229/8 getötet wurde, führte den Oberbefehl beinahe

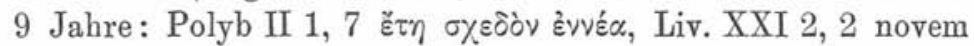
annis; Cornel Hamilcar 4, 2 nono anno postquam in Hispaniam venerat, muf daher im Jahre 237 spätestens nach Spanien gekommen sein. Darum spricht Hannibal vor der Schlacht am Ticinus von der zwanzigjährigen Dienstzeit seiner Soldaten: Liv. XXI 43, 13 ut viginti annorum militiam taceam. Von der Abfahrt Hannibals von Karthago bis zu seiner Rückkehr im Jahre 202 sind 36 Jahre verflossen: Liv. XXX 37, 9 novem annorum a vobis profectus post sextum et tricesimum annum redii, XXXV 19, 1 sub hoc sacramento sex et triginta annos militavi, Oros. IV 19, 4. Mit 9 Jahren verlief Hannibal seine Vaterstadt (Polyb II 1, 6; III 11, 5; Liv. XXI 1, 4; Cornel Hann. 2, 3; Hamilcar 3), 45 Jahre alt sah er sie im

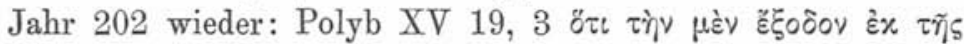

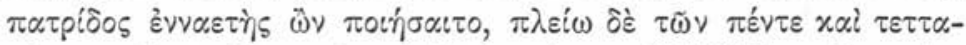

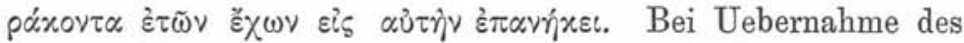
Oberbefehls muf er in einem Alter von 25 Jahren gestanden

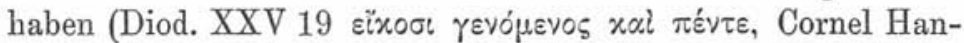

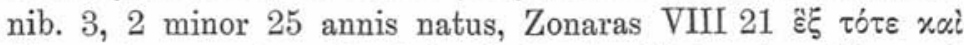

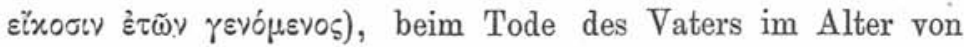


18 Jahren (unrichtig Diod. a. a. 0. = Tzetzes hist. I $27 \pi \varepsilon ́ v \tau \varepsilon$

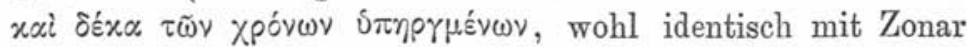
VIII 21, wo es heift, Hamilkar habe den 15 jährigen Hannibal den bekannten Eid schwören lassen). Aus allen diesen Daten ergiebt sich, dabs Hamilkar im Jahre 237 die Unterwerfung Spaniens begann. Im Spätherbst fand die Ausfahrt Hamilkars schwerlich statt, wir werden sie spätestens in den August oder September $237 \mathrm{zu}$ setzen haben. Ihr voraus ging der Krieg mit den Söldnern, der nach Polyb I 88, 7 eine Dauer von 3 Jahren 4 Monaten, nach Diodor XXV 6 von 4 Jahren 4 Monaten, nach Liv. XXI 2, 2 von 5 Jahren hatte. Bei Diodor und Polyb kann es sich nur um eine Verschiedenheit der Ueberlieferung handeln, die Angabe des Livius spricht für die Richtigkeit der Ueberlieferung bei Diodor. Hat Hamilkar im Sommer 237 die Eroberung Spaniens begonnen, dann muf bei einer Dauer von 4 Jahren und 4 Monaten der Söldnerkrieg im April oder Mai 241 seinen Anfang genommen haben, für die Friedensverhandlungen können, der 10. März als Datum der Schlacht bei den ägatischen Inseln vorausgesetzt, daher nur wenige Wochen angesetzt werden. Mag auch der Ausbruch des Söldnerkriegs vor dem definitiven Friedensschluf, der erst im Konsulatsjahr 241/40 (Liv. XXX 40) zustande kam, erfolgt

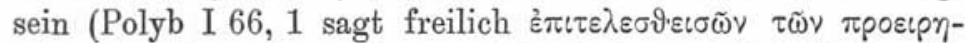

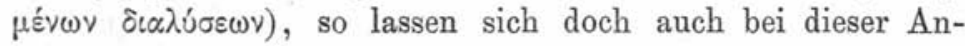
nahme die Ereigńisse nicht in wenige Wochen zusammendrängen. Zunächst gelangt die Nachricht von der Niederlage nach Karthago, wo man sich nicht direkt entscheiden kann, ob man den Krieg fortsetzen soll oder nicht; dann werden Gesandte an Barkas geschickt und diesem der Auftrag erteilt, mit den Römern zu unterhandeln. Diese Verhandlungen vollziehen sich nach dem Zeugnis Cornels und Diodors nicht ohne Schwierigkeiten. Der vereinbarte Präliminarfrieden findet bei den Comitien in Rom keine Annahme und es mußs eine Kommission von 10 Männern nach Sizilien abgehen, welche den definitiven Friedensschluf vollzieht. Für diese Verhandlungen hat man einen längeren Zeitraum anzusetzen, als er geboten wird, wenn man an dem Datum des 10. März fest- 
halten will; die Richtigkeit desselben unterliegt daher auch nach dieser Seite hin erheblichen Bedenken.

Cato und Polybius.

Was die Quellen Polybs betrifft, so macht er als solche Philinos und Fabius namhaft, neben beiden soll er nach Soltau (Wochenschrift für class. Philologie 1888) noch Catos origines benutzt und ihm namentlich sein chronologisches Schema benutzt haben. Er geht dabei von Cato fr. 84 aus: deinde duo et vicesimo anno post dimissum bellum, quod quattuor et viginti annos fuit, Carthaginiensis sextum de foedere decessere und entnimmt daraus den Beweis, daf die Berechnung der Kriegsdauer auf 24 Jahre von Cato, der nach Kriegsjahren rechne, herrühre. Da Polybius, der den Anfang des Krieges in Ol. 129, 1 rücke (I 5, 1) und somit nur 23 Olýmpiadenjahre rechnen dürfe, ebenfalls die Kriegsdauer auf 24 Jahre

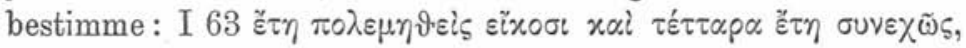
so müsse er, folgert Soltau weiter, von Cato abhängig sein. Der Krieg begann unter dem Konsulate des Appius Claudius und M. Fulvius (Gell. VII 21 anno deinde post Romam quadringentesimo ferme et nonagesimo), und deshalb setzt Polyb, vielleicht dem Vorgange des Timaios folgend (Seipt S. 29), den Beginn in 0l. 129, 1; er endete im Konsulatsjahre' 241/40: Liv. XXX 44, 1 annis ante quadraginta pax cum Carthaginiensibus facta erat Q. Lutatio Catulo A. Manlio consulibus; anders Gellius XVII 21, 4, der den Friedensschluf irrtümlich ins Jahr 240 (consulibus Claudio Centone et M. Sempronio Tuditano) verlegt. Wer den Abstand vom Anfange des Kriegs bis zum Friedensschlusse nach Jahresintervallen berechnete, mußte auf eine 23jährige Dauer des Kriegs kommen, wer aber nach Kriegs- oder Konsulatsjahren rechnete, mufite mit 24 Jahren rechnen. Von einer 23jährigen Dauer des Kriegs sprechen Eutrop. II 27; III, 1 quod per viginti tres annos tractum est, Oros. IV 11, 4 bellum per annos tres et viginti gestum, doch lassen sie den Friedensschlufi im 24. Jahre stattfinden: Oros. IV 11, 3 post annum tertium et vicesimum, Zonar. VIII 17

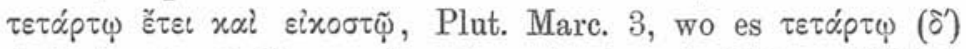

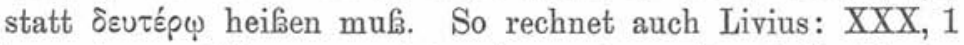
tres et sexaginta annos, tot enim sunt a primo bello Punico 
ad secundum bellum finitum, XXX 44 bellum (d. i. 2. pun. Krieg) initum annis post tribus et viginti P. Cornelio Tib. Sempronio consulibus finitum est septimo decimo Cn. Cornelio P. Acilio Paeto consulibus. Von 24jähriger Dauer des Kriegs

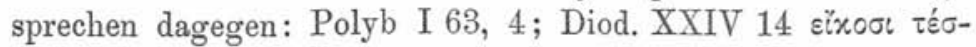

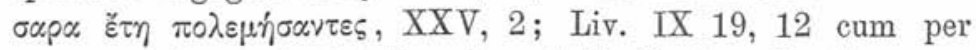
annos quattuor et viginti primo bello Punico classibus cum Poenis certatum recordor, XXI 10, 7 per annos quattuor et

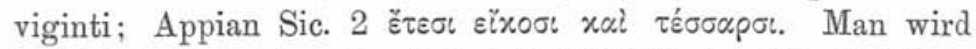
wohl im allgemeinen den Krieg als 24 jährig bezeichnet haben, so gut wie wir den dritten schlesischen Krieg Friedrichs des Großen nur den siebenjährigen nennen, obwohl er erst am 29. August 1756 mit dem Einfall in Sachsen begann und schon am 15. Februar 1763 mit dem Hubertusburger Frieden endete. Eine Abhängigkeit Polybs von Cato daraus folgern zu wollen, dazu liegt nicht der mindeste Anhalt vor, zumal da gar nicht einmal sicher ist, ob die Worte quod quattuor et viginti annos fuit, wirklich von Cato herrühren oder nicht vielmehr Zuthat des Nonnius sind, der das angeführte Fragment überliefert. Es ist kaum wahrscheinlich, daf Cato, nachdem er den ersten punischen Krieg erzählt hatte, bei Beginn des zweiten punischen Kriegs es noch einmal für nötig hielt, die Dauer desselben mitzuteilen. Bei Gellius, der ebenfalls die angeführten Worte Catos mitteilt, lauten sie folgendermafien: XI 10 in M. autem Catonis quarta origine ita perscriptum est: Carthaginiensis sextum de foedere cessere. Abzuweisen ist daher auch die Vermutung Soltaus, daf Polyb, der I 41, 3 das Konsulatsjahr 504 als 14. Jahr bezeichne und somit nur 23 Kriegsjahre rechne, durch den Catonischen Ansatz verleitet sei, die Ereignisse des Konsulats 505 unter zwei Jahre zu verteilen, an beiden Stellen handelt es sich um Irrtümer Polybs.

Als seine Quellen nennt Polyb den Römer Fabius und den Griechen Philinos. Beiden bringt er Mistrauen entgegen, da sie beide nicht die objective Wahrheit berichtet zu haben scheinen, wenn auch absichtliche Entstellung bei beiden nicht anzunehmen ist; es geht ihnen wie Liebhabern, die bei dem Gegenstande ihrer Liebe nur Lichtseiten entdecken (I 14). Dar- 


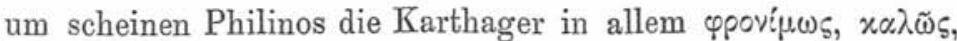
¿̀ $v \delta \rho \omega \delta \tilde{~}$ Philinos sucht Polybius dies I 15 an einem Beispiel zu erweisen, für Fabius verspricht er diesen Nachweis bei späterer Gelegenheit (III 9) und wendet sich nur am Schlusse der Dar-

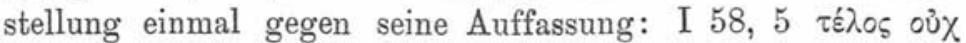

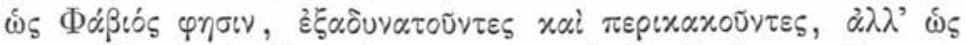

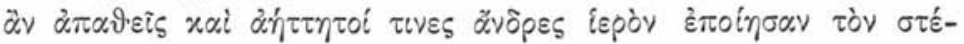
yavov. Bei der hohen Bedeutung, die Polybs Abrißs über die Geschichte des ersten punischen Kriegs zukommt, ist eine Scheidung der Fabianischen Partieen von den aus Philinos geschöpften Abschnitten von hoher Wichtigkeit, aber diese Aufgabe ist, wie Meltzer II S. 557 hervorhebt, durch die Selbständigkeit, mit der Polyp die Quellen behandelt, sehr erschwert. Trotz des teilweise ungünstigen Urteils, das Meltzer über Davin, Beiträge zur Kritik der Quellen des 1. punischen Krieges Schwerin 1889 fällt, scheint mir derselbe die brauchbarsten Ergebnisse gebracht und dieselben weit besser begründet zu haben, als dies Gortzitza, krit. Sichtung der Quellen zum 1. punischen Kriege, Progr. v. Strasburg 1883 gethan hat. Gleichwohl hat auch Davin zu wenig zur Vergleichung die trümmerhafte römische Ueberlieferung herangezogen, aus ihr läbt sich m. E. an verschiedenen Partieen zu greifbaren Resultaten gelangen, ebenso wie durch die Vergleichung mit den Fragmenten der aus Philinos geschöpften Darstellung des Diodors die Benutzung des Agrigentiners seitens des Polybius sich ziemlich sicher feststellen läßt.

Polyb und Fabius.

Um zu bestimmen, welche Partieen Polybius aus Fabius geschöpft hat, hat man auf die mannigfachen Uebereinstimmungen sein Augenmerk zu richten, die er mit der Darstellung Eutrops und des Orosius, besonders in Zahlenangaben, aufweist. Was letzteren betrifft, so hat er im ganzen sich an Eutrop angeschlossen, bietet daneben aber auch selbständige Mitteilungen, die teils auf Livius zurückgehen (IV 7, 9 und per. 17, IV 8, 2 und per. 17), teils bei Florus sich wiederfinden (IV 7, 2 und Florus I 18, 6; IV 7, 8 und Flor. I 18, 7; IV 8, 2 und Flor. I 18, 13; IV 8, 4 und Flor. I 18, 19), 
teils auch anderswoher entlehnt sind (wie z. B. IV 10, 2 aus Cic. in Pison. 43). Wenn auch nicht direkt, so beruht doch in letzter Linie die Darstellung Eutrops und die des Orosius auf Fabius, auf den sich beide an der gleichen Stelle auch einmal berufen: Eutrop III 5 traditumque est a Fabio historico, qui eidem bello interfuit, Oros. IV 13, 6 sicut Fabius historicus, qui eidem bello interfuit, scripsit. Wo Polybius dieselbe Ueberlieferung bietet, wie sie, dürfen wir die Spuren des Fabius bei ihm erkennen, und diese Annahme findet Bestätigung durch Vergleichung mit der anderweitigen römischen Ueberlieferung, wie sie z. B. bei Frontin uns erhalten ist.

So benutzt Polybius den Fabianischen Bericht zunächst bei der Darstellung der Schlacht von Mylä. Die Karthager verloren nach Polyb I 23, 10 im ganzen 50 Schiffe. Wenn auch Eutrop II 20 XXXI naves cepit, XIV mersit, Oros. IV 7, 10 triginta et una naves captae, tredecim mersae andere Verlustangaben mitteilen, so berichtet Polyb I 23, 7 doch

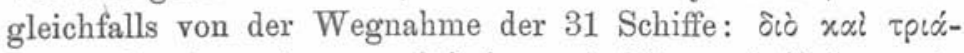

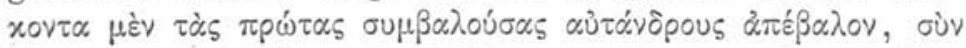

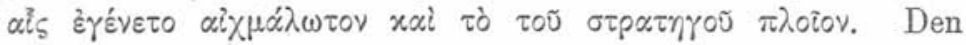
Verlust des Admiralschiffes erwähnt anch Orosius IV, 7, 10 amissa navi, qua vehebatur, der über die Flucht Hannibals ebenfalls die gleiche Nachricht wie Polyb bringt: Oros. IV

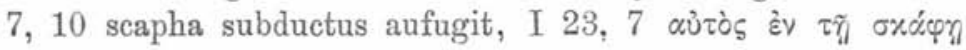
ótẹ́ưøv. Aehnlich spricht sich auch Zonaras aus: VIII c. 11

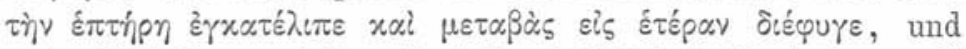

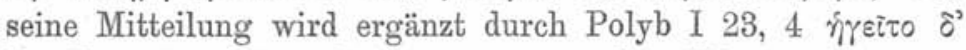

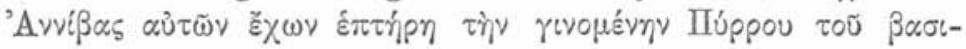

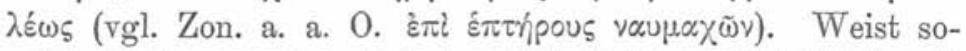
mit c. 23 Spuren der römischen Ueberlieferung bei Polyb auf, so sind dieselben auch nicht in c. 22 bei der Beschreibung der Enterhaken zu verkennen. Ueber dieselben sprechen $\mathrm{Z}_{0}-$

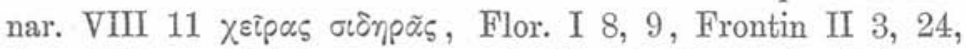
Aur. Victor c. 37 (manus ferreae), übereinstimmend mit ihnen hebt Polyb, der die Einrichtung ausführlicher, als die andern

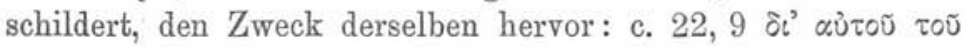

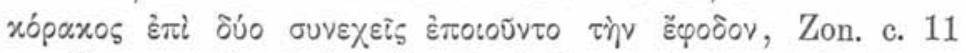

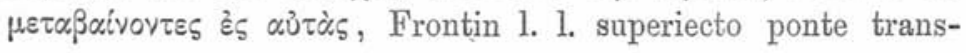
Philologus LX (N. F. XIV), 1 , 
grediebatur Romanus. Gleichen Ursprungs sind auch c. 20 und 21. Mit Zonaras und Orosius weist Polyb auf die Verwüstung Italiens durch die karthagische Flotte hin (I 20, 7, Zonar. VIII, 11, Oros. IV, 7, 7), mit Aurelius Victor (c. 37 quinqueremem hostium pedestribus copiis cepit) auf die Wegnahme eines karthagischen Schiffes (264 v. Chr.), das den Römern bei ihrem Flottenbau als Modell diente (I 20, 15), mit Orosius IV, 7, 9 hat er die gleiche Zahl der bei Lipara unter Cor-

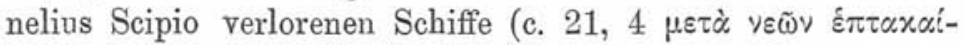

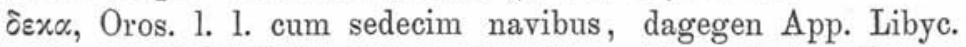
c. $63=22$ Schiffe). Ueber den Gesamtbestand der Flotten gehen die Angaben allerdings auseinander, doch darf man darauf nicht besonderes Gewicht legen, da gerade bei Zahlen leicht Verderbnisse der Ueberlieferung eintreten konnten. Nach Polyb I 20, 10 bauten die Römer 100 Penteren und 20 Trieren, Cn. Cornelius verlor gegen Boodes 17 Schiffe; Boodes hatte bei Lipara 20 Schiffe (I 21, 6), Hannibal, der zuerst der römischen Flotte entgegentrat, verlor die Mehrzahl seiner sich auf 50 Schiffe belaufenden Abteilung (I 21, 11) und hatte bei Mylä 130 Schiffe (I 23, 3). Was die Stärke der römischen Flotte vor Mylä betrifft, so kämpften dort wohl auch die Schiffe der griechischen Bundesgenossen auf Seiten der Römer, und

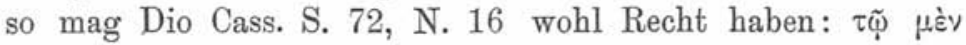

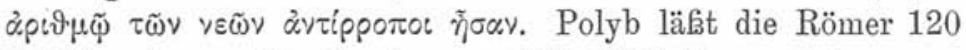
Schiffe erbauen, Orosius dagegen 130: IV 7, 8 nam inter sexaginta dies quam arbores caesae erant, centum triginta navium classis deducta in anchoris stetit. Diese Nachricht steht, von der Differenz in der Zahl abgesehen, gleichlautend bei Florus I 18, 7 intra sexagesimum diem quam silva caesa erat, centum sexaginta navium classis in anchoris stetit, und auch Plin. hist. Nat. XVI 74 mirum apud antiquos primo bello Punico classem Duilii imperatoris ab arbore excisa LX die navigasse (vgl. Liv. XXVIII 45, 21). Nach Diodor XXIII 10 kämpften die Karthager mit 200 Schiffen gegen 120 römische, dies widerstreitet direkt der Angabe Polybs (I 23, 3).

Auch in c. 24, 1-8 folgt Polyb noch derselben Quelle und erzählt in Uebereinstimmung mit Zonaras die Aufhebung der Belagerung Egestas und die Niedermetzlung von 4000 
Römern bei Therma (Diod. XXIII 9, $4=6000$ Römer). Den Tod Hannibals (258) berichtet er in gleicher Weise wie Livius.

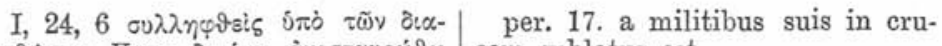

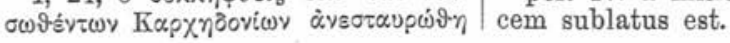

Liegt also in Polyb I 20-24, 8 ein Stück römisch-annalistischer Ueberlieferung vor, so ist die Quelle desselben doch eine andere, als die von Zonaras benutzte. Nach Zonaras (so auch Oros. IV 7,8) erhält Duilius bei Beginn des Feldzugs den Oberbefehl über die Flotte, Cornelius Scipio über das Landheer. Letzterer kümmert sich nicht um den Landkrieg, sondern segelt, durch eine Kriegslist der Karthager getäuscht, nach Lipara, wird aber von Boodes überlistet und gefangen genommen. Während Hannibal die Küste Italiens bloquierte, belagerte Hamilkar Egesta und lockte den Quästor Cäcilius in einen Hinterhalt; dies veranlafte die Römer, Duilius zur Eile anzutreiben. Nach Polyb dagegen ist Duilius nicht der Fübrer

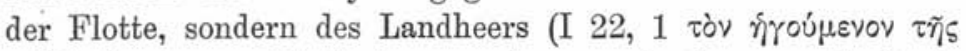

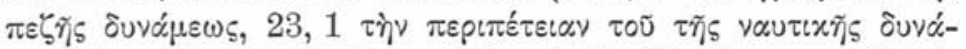
$\mu \varepsilon \omega \varsigma$ îjoupévou). Auch von Verrat, den Boodes gegen Scipio übte, spricht Polyb nicht in I 21, vielleicht in VIII 1, 9, wo

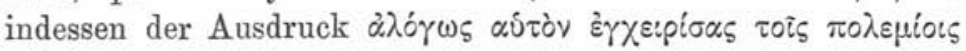
nicht unbedingt den Vorwurf der Treulosigkeit gegen die $\mathrm{Pu}-$ nier ausspricht, Polyb aber auch seine Angabe anderswoher entlehnt haben kann. Am meisten ausgeführt ist die Erzählung von der Ueberlistung Scipios bei Polyän VI 6, 5, vgl. Liv. per. 17 per fraudem velut in colloquium evocatus captus est, Eutrop II 20 fraude deceptus est, Oros. IV 7, 9 quasi ad colloquium pacis evocatus Punica fraude captus atque in vinculis necatus est, Frontin I 18, 11, Val. Max 6, 6, 2. Polybius vertritt die ältere Ueberlieferung im Gegensatz zu der jüngeren, die durch Verrat und Treulosigkeit der Gegner die Niederlage zu erklären suchte.

Auch ein zweiter Abschnitt (c. 25-30) läfit sich durch die Vergleichung mit der römisch-annalistischen Ueberlieferung als Eigentum des Fabius erweisen. Die Konsuln des Jahres 256 führten eine Flotte von 330 Schiffen nach Sizilien: I 25, 7

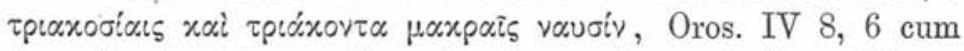
trecentis triginta navibus Siciliam petiverunt (App. Libyca $9^{*}$ 
c. $3=350$ Schiffe). Uebereinstimmung herrscht in den An-

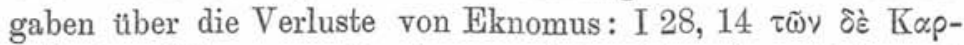

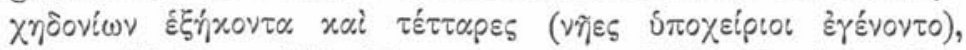
Eutrop II 21 perditis 64 navibus, Oros. IV 8, 7, Aur. Vict. c. 40 naves longas tres et sexaginta cepit; von den Schiffen der Römer wurden 24 vernichtet (I 28, 14, Eutrop. II 21 Romani XXII amiserunt), von denen der Karthager über 30

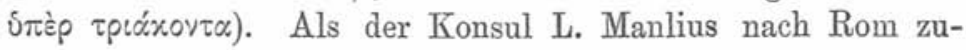
rückkehrte, führte er 27000 Gefangene aus Afrika weg: Eutrop. II 21 XXVII milia captivorum reduxit, Oros. IV 8, 9,

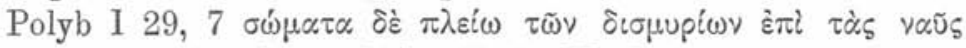

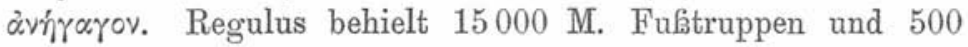
Reiter (I 29, 6). Wenn nach Eutrop II 21 und Oros. IV 9, 3 allein 30000 M. auf Seiten der Römer gegen Xanthippos ge-

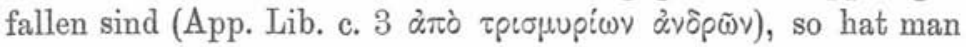
anzunehmen, daf das Heer des Regulus durch afrikanische Truppen verstärkt war. In c. $30 \mathrm{ff}$. wendet sich Polyb einer anderen Quelle zu, bringt in 34, 8 aber wieder die Verlustangaben des Fabius:

$\S 8$. $\pi \varepsilon v \tau \alpha x o ́ \sigma t o r$ of $\mu \varepsilon \tau \dot{\alpha}$ Mápxov| Eutrop. II 21. nam duo milia ex

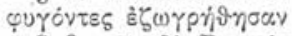

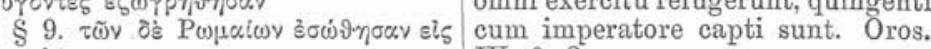

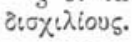
IV, $9,3$.

Die Konsuln des Jahres 255 haben nach Polyb eine Flotte von 350 Schiffen (I 36, 10), nach Eutrop II 22 und Oros. IV 9, 5 von 300 Schiffen. Am hermäischen Vorgebirge nahmen nach Polyb I 36, 11 die Römer 114 Karthagische Schiffe weg, nach Eutrop II 22 und Oros. IV 9, 6 bohrten sie 104 in den Grund und nahmen 30 weg (24 Schiffe nach Diod. XXIII 18, 1). Hier finden sich Abweichungen im einzelnen, und doch müssen Polyb und Eutrop (Orosius) die gleiche Vorlage benutzt haben. Bei Camarina werden nach Eutrop II 22 von 464 Schiffen der Römer nur 80 gerettet, Polyb dagegen beziffert die Gesamtsumme auf 364, die geretteten auf 80. Hier setzt Eutrop die bei Polyb überlieferten Zahlen 114 (I 36,11 ) voraus: $350+114$ $=464$, bei letzterem ist dagegen die Gesamtsumme falsch überliefert (364 statt 464). Orosius geht hier seinen eigenen Weg und berichtet, ohne den angegebenen Verlust von 9 Schiffen $(9,6)$ in Betracht zu ziehen, auf Grund der verderbten 
Zahl Eutrops nach eigener Berechnung : $\$ 8$ nam de trecentis navibus ducentae viginti perierunt, octoginta vix abiectis oneribus liberatae sunt. Dies Resultat findet seine Bestätigung: auch durch folgende Polyb und Eutrop gemeinsame Mitteilung:

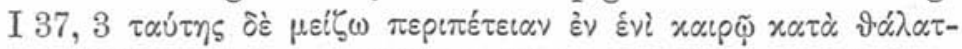

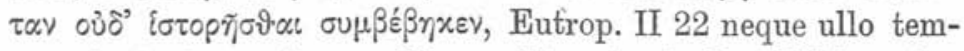
pore tanta tempestas maritima audita est. Andere Zahlen über die Verluste bei Camarina bietet wieder Diodor: XXIII 18, 1

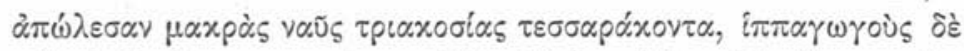

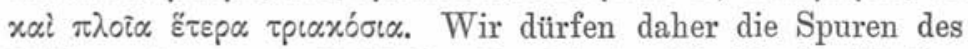
Fabius erkennen in I 25, 7-29; 34, 9-12; 36, 5-37, 2.

Wie in den Zahlenangaben, berührt sich die Darstellung Polybs auch in anderen Punkten mit der römischen Ueberlieferung. So berichten Zonaras (VIII 12) und Polyb (I 25, 7) das Anlaufen der römischen Flotte in Messana, Polyb und Orosius heben hervor, daf drei karthagische Feldherrn gegen

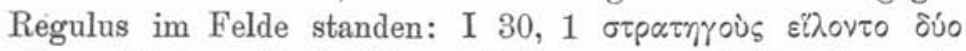

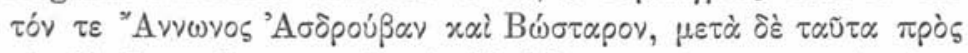

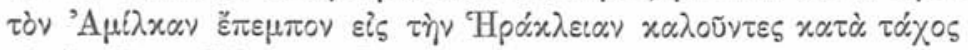

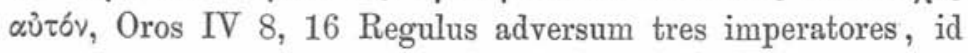
est Hasdrubales duos et accitum ex Sicilia Hamilcarem atrucissimum bellum gessit. Ueber Xanthippos sind zwei Erzählungen Frontins (II 2, 11 und II 3, 10) erhalten, die römischen Ursprungs sind (II 2, 11 Poenos in plana deduxit, Oros. IV 9, 2 Poenorum copiis in campum deductis, Zon.

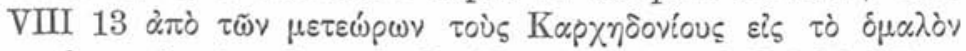
$\left.x \alpha \tau \eta^{\prime} \gamma \alpha \gamma \varepsilon \gamma\right)$; sie geben uns den Beweis, dafs auch Polybius Darstellung in c. $32-34$ (wo Davin S. 17 Philinos als Quelle annimmt) einer römischen Quelle entstammt:

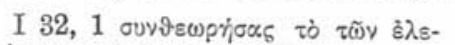

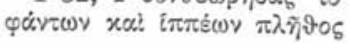

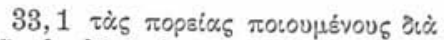

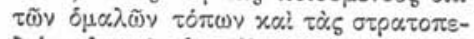

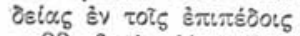

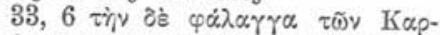

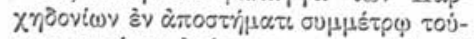

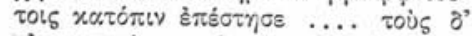

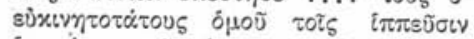

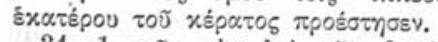

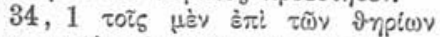

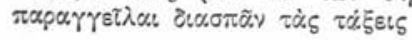

II 2, 11 cum animadvertisset Afros quidem, qui equitatu et elephantis praestabant, colles sectari.

ib. in plana deduxit.

II 3, 10 levem armaturam in prima acie collocavit, in subsidio autem robur exercitus.

II 3, 11 per elephantos dissipatis ordinibus. 


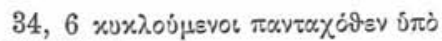
$\tau \tilde{\omega}$ เ

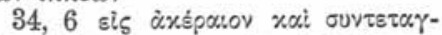

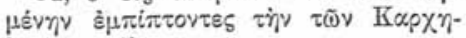

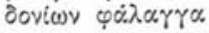

II 3, 10 et ipsi circumierunt

II 3,10 exceptumque iam hostem a robustioribus.

Aus Frontin gewinnen wir daher die Bestätigung unserer Annahme, daß3 Polybius Erzählung aus Fabius entlehnt ist.

Nach seinem Siege über Regulus verlief Xanthippos Karthago aus Furcht vor dem Neide der Karthager: I 36, 2

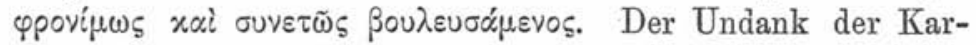
thager gegen ihn bot den Römern später ein willkommenes Thema (Zonar. VIII 13, Appian Punic. c. 4; Valer. Max. IX 6 ext. 1, Tzetzes hist. III 358), und auch Polyb scheint eine ähnliche Erzählung zu kennen, über die er bei geeigneter Gelegenheit sich auszusprechen verheißst. Man könnte daher geneigt sein, die von ihm mitgeteilte Version auf Philinos zurückzuführen, wenn nicht auch Orosius IV 9, 4 die gleiche Mitteilung böte: Xanthippus tam audacis facti conscius rerum instabilium mutationem timens ilico ex Africa in Graeciam migravit. Vielleicht berichtete so Fabius, dessen Darstellung sich somit als frei von der späteren tendenziösen Erdichtung erwiese. Auch für die Heldenthat des römischen Leonidas, mag er nun Caedicius oder Laberius oder M. Calpurnius heißen, wird wohl das Zeugnis Catos oder des Claudius Quadrigarius geltend gemacht, nicht das des Fabius: Liv. per. 17, XXII 60, 11; Val. Max. VI, 2; Flor. I 18, 13; Aur. Vict. 39, Oros. IV 8, 2, Zonar. VIII 12, Frontin I 5, 15, Gellius III 7. Fern liegt Polybius und wohl auch Fabius die Ruhmredigkeit, welche uns in der Erzählung über die Gesandtschaft Hannos bei Zonar. VIII 12 (Dio Cass. S. 74 No. 21) und Valer. Maximus VI 6, 2 entgegentritt, keinerlei Erwähnung geschieht der großen Schlange am Bagradas, deren Liv. per. 18, Val. Max. I 8 ext. 19, Florus I 18, 20, Oros. IV 8, 10 ff., Plin. N. H. VIII 14, Gellius VII 3, Zonaras VIII 13 (Dio Cass. S. 74, 20) gedenken. Dem Xanthippos überlassen nach Polyb I 32, 5 die karthagischen Führer nur die Einübung des Heeres und vor der Schlacht die Führung der Truppen, nach Zonar. VIII 13 dagegen wird er zum Feldherrn der Karthager mit unumschränkter Vollmacht gewählt. Seinen Sieg schreibt Zonaras dem Umstande zu, dak 
er die sorglos gelagerten Römer überfälltt; als Tpaıxòs ist er von den Konsuln verachtet, auch dies weist auf spätere Ausgestaltung des Berichts, wie ihn Zonaras giebt, hin. Selbstredend fehlen bei Polybius die Erzählungen über den Martertod des Regulus, wie sie Cicero de off. III 26, 99, de fin. I 65, V 82, in Pis. $\$ 98$, pro Sestio $\S 127$, Horat. III 5, Liv. per. 18, Florus I 18, 24-26, Eutrop II 25, Oros. IV 10, 1, Gell. VII 4, 1 (Tuditanus und Tubero), Valer. Max. I 1, 14, Polyän VIII, 12, Appian Libyca c. 3, Sicil. c. 2, Zonar. VIII 15 ( $\omega_{\varsigma} \hat{\eta}$

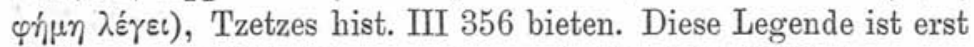
später ausgebildet (Jäger, Progr. d. Friedrich-Wilhelmsgym. Köln 1878) und auch Fabius fremd. Polyb berichtet auch nichts von einer Schlacht bei Clupea, die Oros. IV 9, 7 und Zonar. VIII 14 melden.

Nach der Vernichtung der Flotte bei Camarina bauten

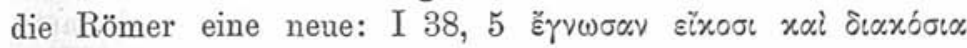

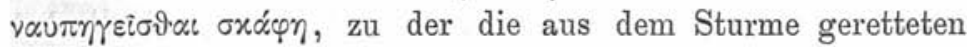

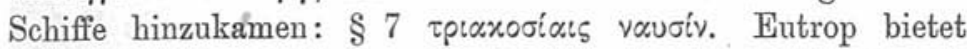
andere Zahlen: II 22 ducentas naves reparaverunt, II 23 cum ducentis sexaginta navibus (Oros. IV 9, 10), doch wäre hier der Ausfall von XX denkbar, da Polyb auch von Diodor in

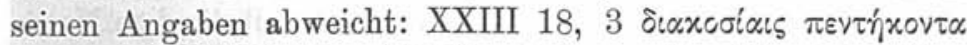
vauoiv. Den Verlust an Schiffen beim zweiten Sturm beziffern alle auf 150: Polyb I 39, 6, Oros. IV 9, 11 (naves one-

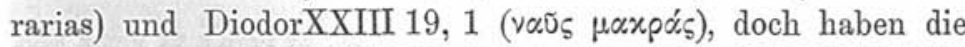
Karthager nach Diodors Erzählung die römische Flotte in

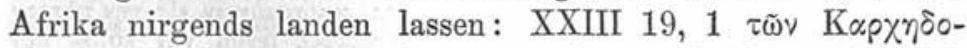

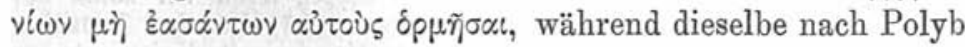

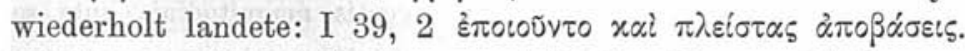
Letzterer gesteht indessen $\mathrm{zu}$, daf die Römer nichts ausrichteten, Orosius weif dagegen von reicher Beute und der Eroberung vieler Städte zu berichten, vertritt also Polyb gegenüber die jüngere, weiter ausgeschmückte römische Ueberlieferung.

Während der Schlacht bei Panormos sind nach Polyb I 40, 15 nur 10 Elefanten in die Hände der Römer gefallen, alle anderen erst nach der Schlacht. Thre Zahl bestimmt er nicht, Hannibal hatte nach I 38, 2 im ganzen 140 Elefanten 
nach Sicilien geführt. Diodor XXIII 21 weiß nur von 60 Elefanten, die weggenommen wurden, nach Liv. per 19 und Zonar. VIII 14 sind es 120 , nach Plin. N. H. VIII 6 gar 142 , nach Dion. Hal. II $66=138$, nach anderen $=140$, nach Florus I 18, 27 nur 100. Eutrop II 24 läßst Hasdrubal mit 130 Elefanten nach Sicilien kommen, 26 sollen in der Schlacht gefangen genommen sein, die anderen nach derselben, sodaj 130 im Triumphzuge des Metellus aufgeführt wurden. $\mathrm{Ob}$ diese Zahlen richtig überliefert sind, darf bezweifelt werden; Orosius IV 9, 15 behauptet, 26 Elefanten seien nicht eingefangen (intercepti), sondern getötet worden (interfecti), und rechnet für den Triumphzug blos 104 Elefanten. Daf Eutrop und Orosius auf die gleiche Vorlage zurückgehen, ist unbestreitbar; daraus folgt aber, dafs Polybs

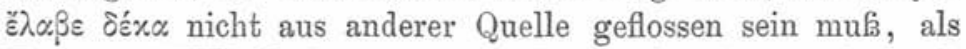
Eutrops XXVI elephantos cepit. Dieser Annahme steht auch nicht Polybs Gesamtzahl 140 entgegen, denn seine Quelle bot die Zahl 130. Der Beweis dafür läßst sich aus Frontin II 5, 4 ob ingentem eius exercitum et CXXX elephantos intentior führen, denn das angeführte Strategem schließst sich so genau an Polyb II 40 an, daf man diesen fast als Quelle Frontins ansehen könnte, wenn letzterer nicht auch selbständige Nachrichten brächte.

II 5, 4. intra Panormum copias tenuit

praecepit hastatis, tela in beluas iacerent protinusque se intra munimenta reciperent

ea ludificatione rectores elephantorum concitati in ipsam fossam elephantos egerunt.

partim multitudine telorum

confecti partim retro in suos acti totam aciem turbaverunt

tunc Metellus hanc opperiens occasionem cum toto exercitu erupit et aggressus a latere Poenos cecidit

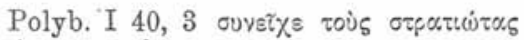

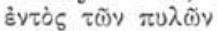

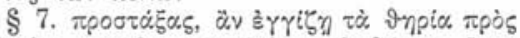

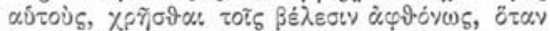

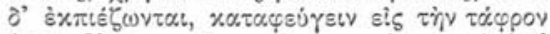

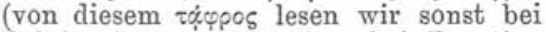
Polyb nichts, wohl aber bei Frontin: fossam ingentis magnitudinis ante se duxit).

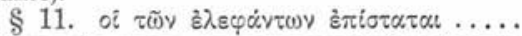

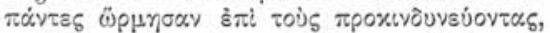

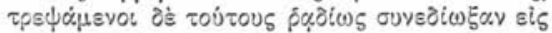
$\tau \dot{\eta} \nu \tau \dot{\alpha} \varphi \varphi p o v$

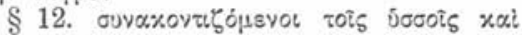

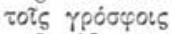

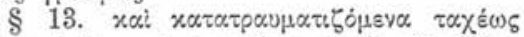

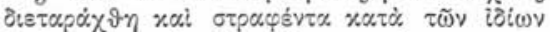

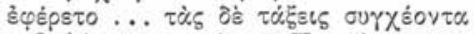

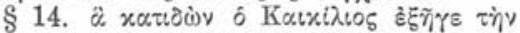

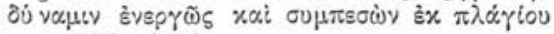

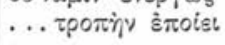


Den Bericht über die Schlacht von Panormos verdankt Polyb also Fabius. Philinos suchte die Niederlage der Karthager damit zu erklären, dafs er die Schuld den trunkenen Kelten beimaj. Von Zonaras weicht Polyb darin ab, dafs er nichts über das Erscheinen der karthagischen Flotte vor Panormos berichtet; auch unterläßft er nähere Angaben über den Transport der Elefanten (vgl. Plin. H. N. VIII 6 u. Frontin I 7,1).

Die Zahl der für das Jahr 250 fertiggestellten Schiffe beträgt nach Polyb I 41, 3 und Oros. IV 10, 2 nur 200, während die Flotte nach Diod. XXIV 1, 1 eine Stärke von 240 Schiffen hat. Auf Fabius ist auch Polybs Darstellung der Schlacht von Drepana zurückzuführen (c. 49-51):

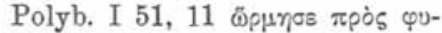

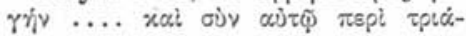

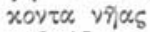

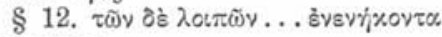

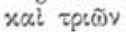

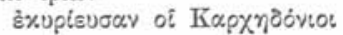

Eutrop II 26 nam ex CCXX (Oros. CXX) navibus cum XXX fugit, nonaginta cum pugnatoribus captae sunt, ceterae demersae

vgl. Oros. IV 10, 3, Frontin II 13,9 , wo in cod. $P$. triginta gelesen wird.

Andere Zahlen hat Diod. XXIV 1,5: vã́s ह̇ं

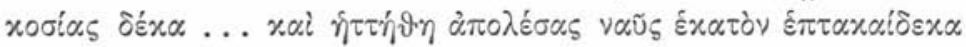
xal ăvôpas ôtopupious. Ueber den Frevel und die Bestrafung des Claudius Pulcher (Liv. per. 19, Cicero de nat. deor. II 3, de divin. I 16, 29, Serv. zu Verg. Aen. VI 198, Val. Max. II 4, 3, Flor. II 18, 29; Eutrop II 26) schweigt Polyb, doch

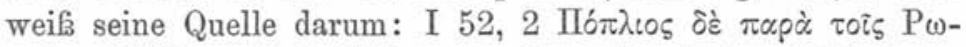

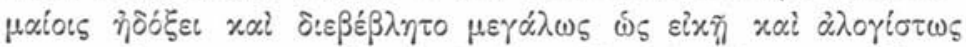

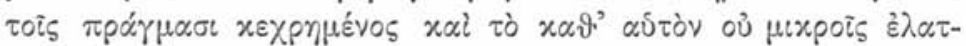

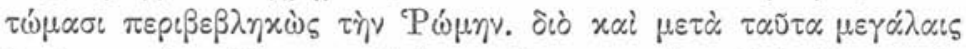

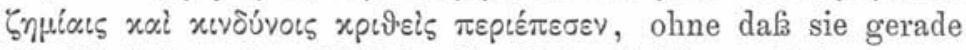
die Niederlage dem Religionsfrevel des Feldherrn beigemessen zu haben scheint.

So lassen sich 4 grökere Partieen der Darstellung Polybs mit grofer Wahrscheinlichkeit aus Fabius herleiten, den Vorzug scheint aber der Schriftsteller dem Agrigentiner Philinos gegeben zu haben, wie die Vergleichung mit Diodor ergiebt. Polybius und Philinos.

Philinos stammte aus der sicilischen Stadt Agrigent, die nach der Eroberung durch die Römer schwer die Hand des 
Siegers empfinden mufte. Er stand daher mit seinen Sympathieen auf der Seite der Karthager und war mit bitterem Hasse gegen die Römer erfüllt. Seine Darstellung charakterisiert Davin treffend mit den Worten: "wo sich eine gewisse Anteilnahme an der karthagischen Sache, ein gewisser Gegensatz gegen die Römer verrät, wo sich jener hellenische - sogar ein local-patriotischer Standpunkt findet, wo ferner die Merkmale jener populär-philosophischen Anschauung hervortreten, und wo das alles sich im Verein mit reichem historischem Detail zeigt, haben wir das Recht, auf Philinos als Quelle zu schliefien ". Benutzt ist er von Diodor, "der in allen wesentlichen Punkten den Philinos wiedergiebt" (Meltzer II S. 557). Wo daher zwischen Diodor und Polybius sich Uebereinstimmung bemerklich macht, hat man Benutzung des Philinos bei beiden anzunehmen.

Nach der gleichen Quelle erzählen Diodor und Polyb die Belagerung Messanas durch Hiero und die Karthager und die Unterstützung der Mamertiner durch die Römer: 1) Bündnis der Syrakusaner mit den Karthagern, 2) die karthagische Flotte steht bei Pelorias, Polyb I 11, 6, Diod. XXIII 1, 3,

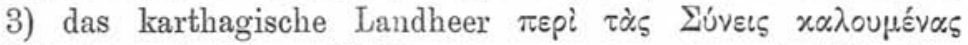
(Eủveī), ebendas. 4) Hiero am sogenannten chalkidischen Berge, Polyb I 11, 8 u. Diod. XXIII 1, 3. Wenn bei Polyb I 11, 9 u. 10 der Konsul Appius Claudius erst nach seiner Landung in Messana die Unterhandlungen mit Hiero und den Karthagern anknüpft, nach Diodor (auch nach Zonaras) schon von Rhegion aus, so ist diese Verschiebung begründet durch die Kürzung, die Polyb mit dem ausführlicheren Berichte seiner Quelle vornimmt. Nach seiner Niederlage lassen Polyb I 11, 15 und Diod. XXIII 3 den König Hiero direkt nach Syrakus fliehen, während er nach Zonaras VIII 9 zunächst in die Berge und erst später nach Syracus floh. Am Tage nach der Besiegung Hieros schlug Claudius die Karthager und zwang sie zur Flucht in die nahegelegenen Städte. So erzählen Polyb

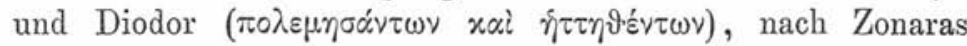
(Dio S. 71, 12) dagegen hielten sich die Karthager in ihrem Lager, das sie, solange Claudius in Messana war, nicht mehr zu verlassen wagten. Mit dieser Darstellung liefe sich der 
von den Fasten erwähnte Sieg des Konsuls M. Valerius Messala im Jahre 263, dessen auch Plin. H. N. XXXV 7 gedenkt (über andere Erwähnung vgl. Meltzer II S. 561) vereinen, erst durch diesen wurden die Karthager genötigt, ihre Stellung bei Messana aufzugeben. Polyb hegt Mistrauen gegen Philinos, benutzt ihn aber gleichwohl, indem er dabei einzelne Angaben umgestaltet, wie sie ihm zu passen scheinen. So giebt er das Motiv, das Philinos für Hieros Abzug anführt: 15, 3 ròv

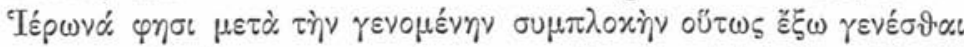

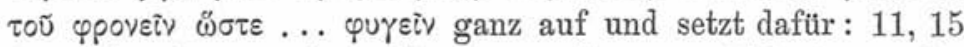

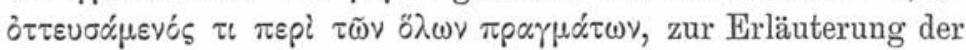
Situation dient Diod. XXIII 3 vopi

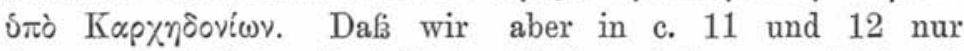
den umgearbeiteten Bericht des Philinos haben, ergiebt sich aus der Vergleichung mit c. 15, wo Polyb denselben kritisiert:

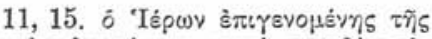

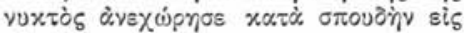

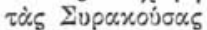

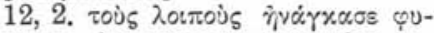

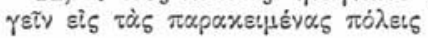

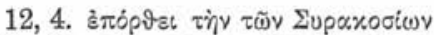

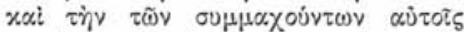

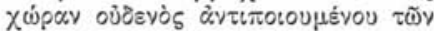

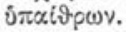

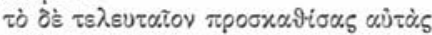

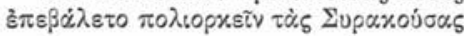

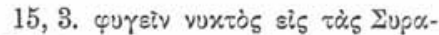
жоن்

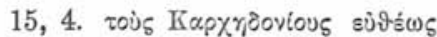

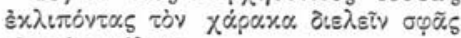

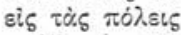

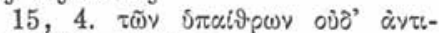

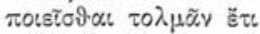

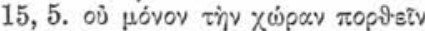

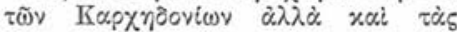

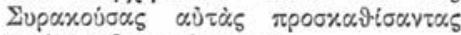

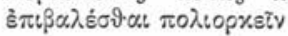

Auch in dem Excurs über die Bedeutung des ersten punischen Kriegs verwendet Polyb Gedanken des Philinos, wie er dies gerade in allgemeinen Betrachtungen mit Vorliebe thut:

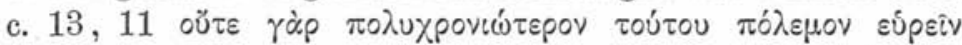

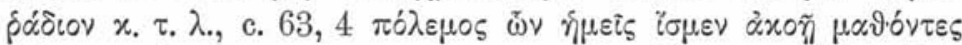

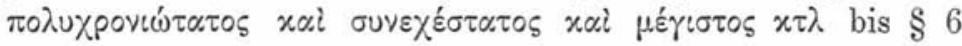

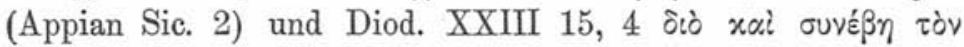

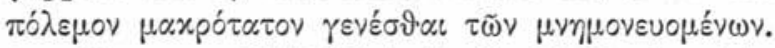

Ebenso erzählt Polyb die Geschichte des Jahres 263 nach Philinos (c. 16 u. 17, 1-5). Beide Konsuln werden nach Sicilien geschickt (Polyb. Diodor. Zonaras), und es gelang ihnen, die meisten Städte auf ihre Seite zu ziehen (c. 16, 2 u. Diod. XXIII 4). Hiero schloß daher Frieden mit den Römern: 


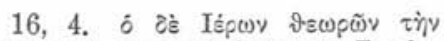

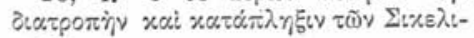
$\omega \tau \tilde{1}$

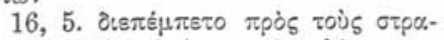

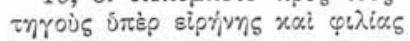

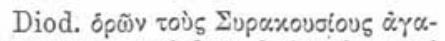

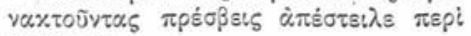

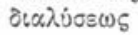

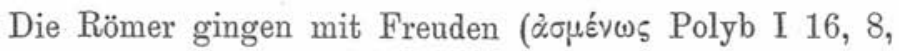
Diod. a. a. 0.) auf die Friedensvorschläge ein und verlangten die Auslieferung der römischen Kriegsgefangenen ohne Lösegeld (I 16, 9, Diod. a. a. 0.).

Seiner griechischen Quelle entnimmt Polyb auch die Geschichte der Belagerung Agrigents. Obwohl Zonaras in einzelnen Zügen mit ihm übereinstimmt, so weicht er doch in anderen Punkten erheblich von ihm und Diodor ab. Wenn er behauptet, der karthagische Feldherr Hannibal sei uur mit wenigen aus Agrigent entkommen (Oros. IV 7, 6 Hannibal cum pancis diffugit), die anderen seien von den Römern und Agrigentinern getötet worden, so steht dem die Behauptung Polybs entgegen, er sei mit seiner ganzen Streitmacht entkommen. Diodors Fragmente betreffen hauptsächlich Mitteilungen über die Stärke und Verluste beider Heere, in diesem Punkte miktraut Polyb Philinos und unterdrückt in der Regel derartige Angaben. So schätzt Diodor das Belagerungsheer auf 100000 Mann, während Polyb nur von der Anwesenheit der beiden konsularischen Heere spricht ( $\mu \varepsilon \tau \grave{\delta} \tau \tilde{\omega} v \quad \sigma \tau p \alpha \tau o \pi \varepsilon ́ \delta \omega \nu$, irrig Ihne II S. 40 A. 27). Die Zahl der eingeschlossenen waffenfähigen Männer berechnet Polyb I 18, 7 auf nicht ganz 50 000, die Zahl der Elefanten Hannos I19, 2 auf 50. Diodor giebt nach Philinos, auf den er sich beruft, die Stärke von Hannos Heer (anders Oros. IV 7, 5), die Verluste der Karthager und Römer, die Zahl der in die Sklaverei verkauften Agrigentiner an. Wenn er dem Heere Hannos 60 Elefanten folgen läßst, so ist auf diese Abweichung kein großes Gewicht zu legen (Polyb I 19, 2 $\left.\pi \varepsilon \rho i \pi \varepsilon v \eta_{\eta} x o v \tau \alpha\right)$, ebensowenig darauf, daß sich bezüglich der Verluste Hannos Polyb mit der unbestimmten Mitteilung begnügt, fast das ganze Heer Hannos sei vernichtet worden. Den $\varepsilon \xi \xi \mu \tilde{\eta}$ vas, welche Diodor als Dauer der Belagerung annimmt, entsprechen gewif auch die detaillierten Zeitangaben

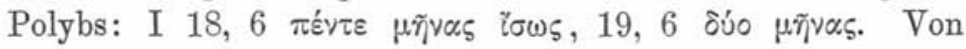
diesen geringfügigen Differenzen abgesehen, deckt sich Diodors 


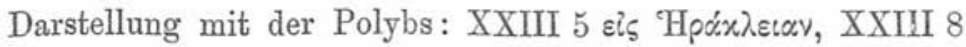

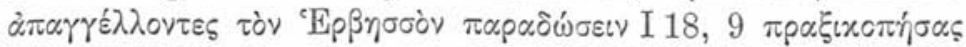

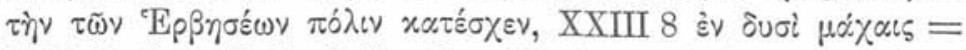
I 19, 2 ff. u. I 19, 9 ff. Für die Autorschaft des Philinos sprechen die genauen topographischen Angaben (I 17, 8 हे v

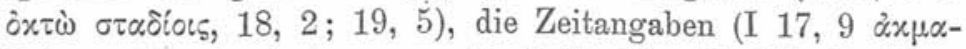

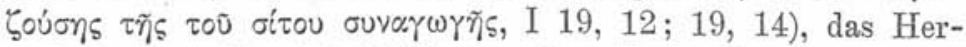
vorheben der Thätigkeit Hieros, der die bereits am Erfolge verzweifelnden Römer zum Ausharren ermutigte: Der Untergang seiner Vaterstadt war bei Philinos gewif mit besonderer Ausführlichkeit geschildert.

In I 24, 5 u. 6 greift Polyb mit der Erzählung von Hannibals Tod bereits in das Jahr 258 über, um mit $\$ 8$ zu dem Jahr 259 zurückzukehren. Wir haben hier einen Wechsel der Quelle anzunehmen, in \$ 8-13 werden nach Philinos kurz die Ereignisse der Jahre 259 und 258 erzählt. Von dem Kriege auf Sardinien und Corsika (Liv. p. 17, Eutrop. II 20, Oros. IV 7, 11; Flor. I 18, 15 u. 16; Val. Max. V 1, 2; Zonar. VIII 12) berichten Polyb und Diodor weder unter dem Jahre 259 noch unter 258 (Oros. IV 8, 4, Zon. VIII 12), ebenso wenig von der Verschwörung der Sklaven und socii novales (Oros. IV 7, 12, Zon. VIII 11). Die Konsuln des Jahres 258 wandten sich gegen Panormos, wo die karthagischen Streitkräfte überwintert hatten (I 24, 9) und nahmen

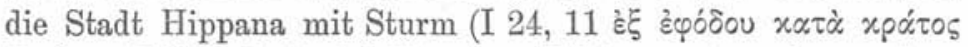

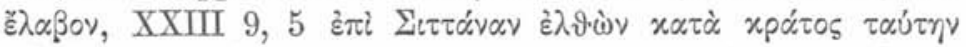
$\varepsilon\lfloor\lambda \varepsilon \vee)$, ferner Myttistraton, Kamarina, Enna und andere Plätze; darauf schickten sie sich zur Belagerung Liparas an. Ohne Bedeutung ist es, daßs bei Diodor die Einnahme Hippanas der Wegnahme Ennas erst folgte. Myttistraton wurde, wie Diodor berichtet, schon zum 3. Male belagert, das soll wohl der Plural

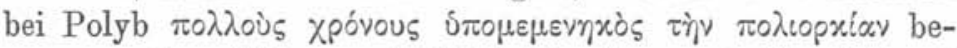

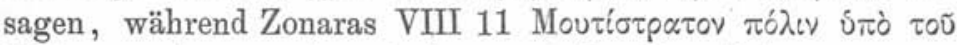

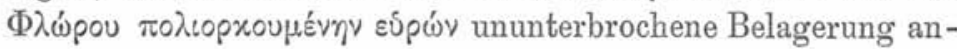
zunehmen scheint. Kamarina und Enna waren von den Rö-

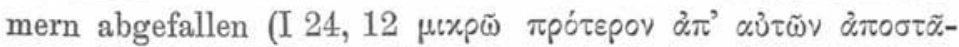
$\sigma \alpha \nu$, Diod. XXIII 9, 4 'A

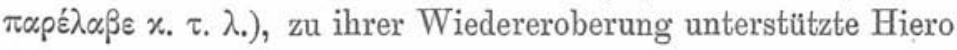


die Römer mit Kriegsmaschinen (Diod. XXIII 9, $5 \pi \alpha \rho$ ' 'T $\varepsilon$ -

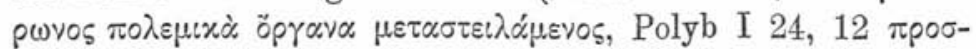

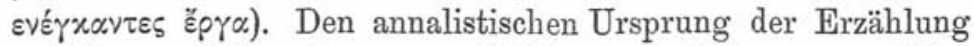

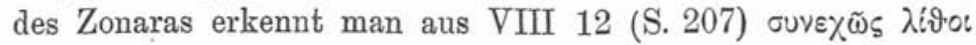

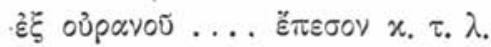

Auch die Schlacht bei Tyndaris (c. 25, 1-4) wird von Polyb im Anschlußs an Philinos erzählt. Bei ihm ist die Schlacht unentschieden und der Verlust der Römer ebensogrof, als der der Karthager, Zonaras dagegen macht aus ihr einen großen Sieg

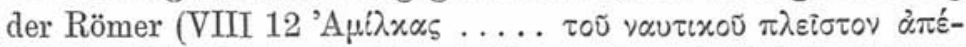
$\beta \alpha \lambda \varepsilon v)$. Die gleiche Quelle wie Zonaras benutzt Polyän VIII 20

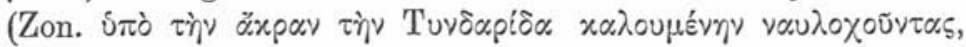

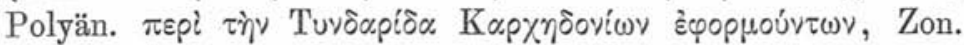

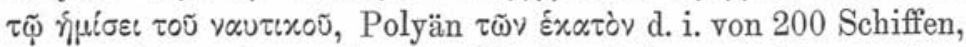

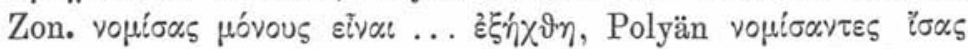

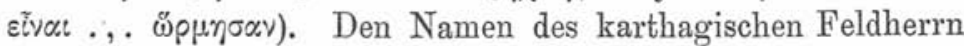

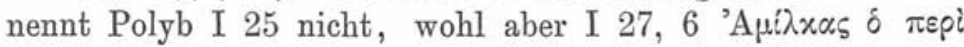

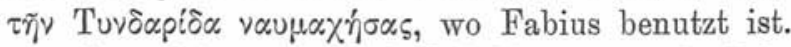

In c. 30 wendet sich Polybius etwa mit $\$ 6$ wieder Philinos zu, seiner Auslassung in $\S 6-10$ entsprechen Diodor

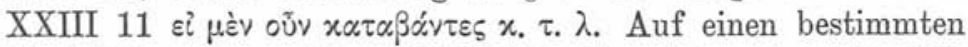

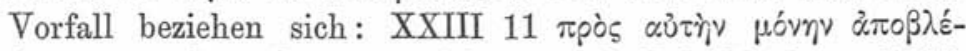

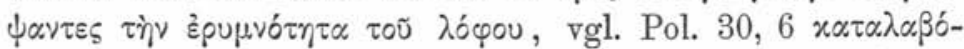

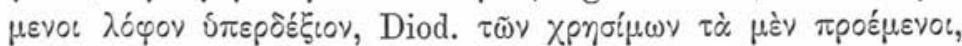

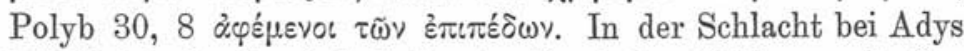
läßt Polyb der Tapferkeit der karthagischen Söldner volle Gerechtigkeit widerfahren, dieselben werfen sogar das erste Treffen, während nach Zonaras die Römer die Feinde in den Betten überraschen und dieselben teils in den Betten, teils auf der Flucht niedermachen. Unzweifelhaft ist der Ursprung aus Philinos für c. 31 :

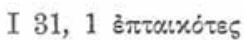

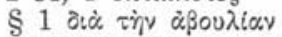

$\$ 3$ ठvovupia

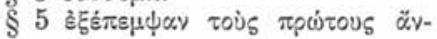
ठpa.s cetั

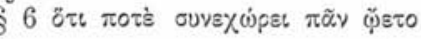

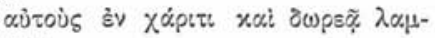

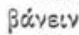

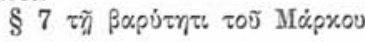

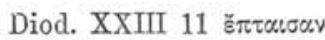

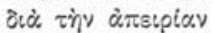

12. $\dot{\alpha} \vartheta$

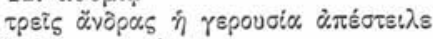

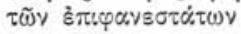

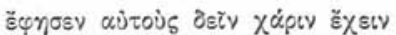

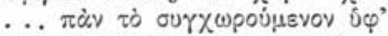

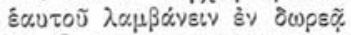

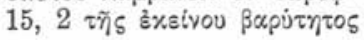




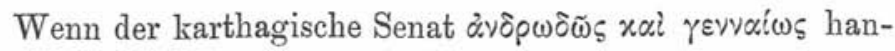
delte, so hebt Polyb I 14, 3 dies gerade als charakteristisch für Philinos hervor.

Auch die Betrachtungen, die Polybius an die Niederlage des Regulus knüpft, hat Diodor c. 15 aus Philinos uns erhalten:

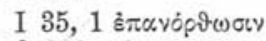
zoiss

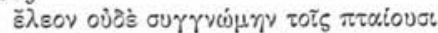
$\lambda \dot{\alpha} \zeta$

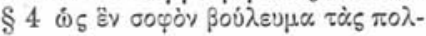

\section{$\chi \varepsilon l p \alpha_{5} v เ x \tilde{\alpha}$}

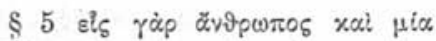
ชrópท

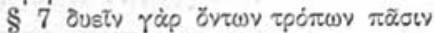

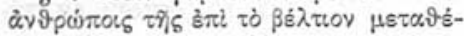

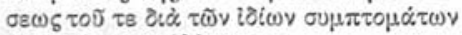

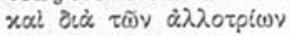

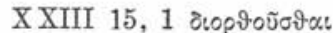

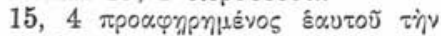

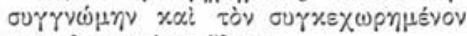

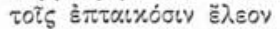

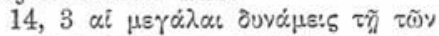

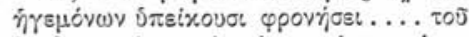

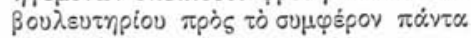

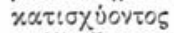

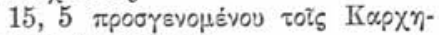
Zoviots sิvòs aेvరిpós.

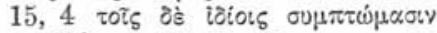

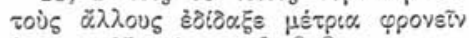

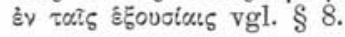

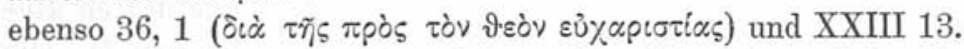

Der gleichen Quelle gehören die allgemeinen Betrachtungen an, welche wir über die Bestürzung der Römer in I 39, 7-15 lesen. Während Polyb das Jahr 252 übergeht, nimmt er in diesem Abschnitte doch auf die in dieses Jahr fallende Wegnahme Liparas und Thermas Bezug (Diod. XXIII 20). Mit Eutrop II 23 und Oros. IV 9, 12 berichtet er zwar den Entschluf der Römer, nur noch 60 Schiffe in Dienst zu stellen, aber diese sind dazu bestimmt, die Heere in Sizilien mit Lebensmitteln zu versorgen, während sie nach Eutrop, Orosius und Zonaras die Küste Italiens schützen sollen: Eutrop II 23 ad praesidium Italiae, Oros. IV 9, 12 ad subsidium Italiae,

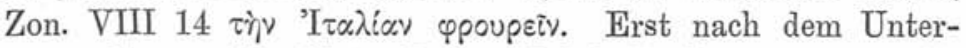
gange der zweiten Flotte bringt Polyb die Erörterungen, die Diodor nach der Niederlage des Regulus anstellt, daher ist

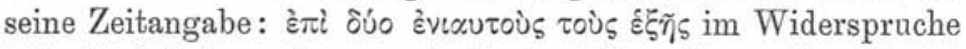

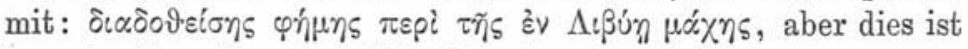
nur ein Versehen bezüglich der Anordnung:

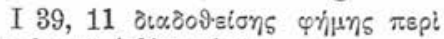

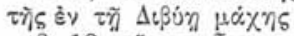

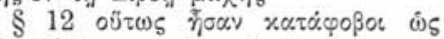

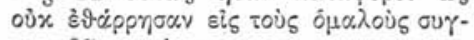

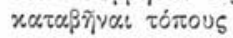

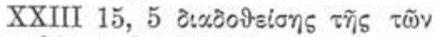

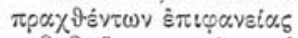

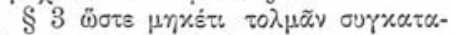

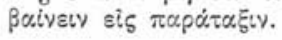

In dieser allgemeinen Betrachtung greift Polyb schon ins 
Jahr 250 hinüber und erwähnt die Konsuln dieses Jahres. Auf Philinos geht weiter Polybs Darstellung von der Belagerung Lilybaions zurück (c. 42-48), wenn er auch zunächst noch nach Fabius die Stärke der römischen Flotte berechnet (I 41, 3). Wenn Diodor ganz andere Zahlen überliefert, so findet dies seine Erklärung in dem Miftrauen, das Polyb in diesem Punkte gegen Philinos hegt. Die Zahl der Belagerer stellt sich bei Diodor XXIV 1, 1 auf 110000 M., der Belagerten auf 7000 M. Fufsoldaten und 700 Reiter, zu denen dann noch 4000 Mann unter Adherbal hinzutraten; die 110000 Römer schmolzen bei Polyb I 45, 8 auf etwas mehr denn 20000 zusammen (Oros. IV, 10, 2 quattuor legionibus), der Belagerten sind es statt 11000 auch 30000 (I 45, 8 of घेx

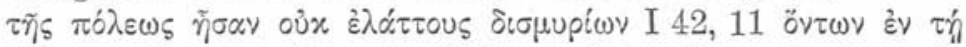

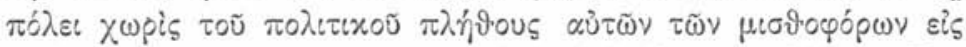

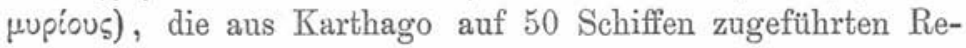
serven erreichen die Stärke von 10000 M. (I 44, 1 u. 2). Die Zahl 10000 scheint für Polyb eine Art Notbehelf zu sein, er

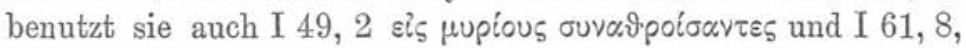
wo ihm ebenfalls die Angaben seiner Quellen bedenklich erscheinen. Selbstverständlich konnte Polyb nach Reduzierung der Stärkeangaben keinen Gebrauch mehr von den Verlustan-

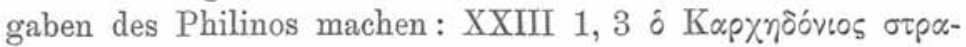

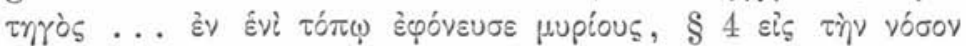

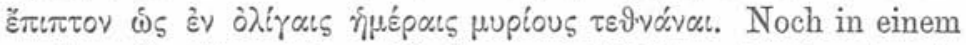
zweiten Punkte stehen Diodor und Polyb mit einander in Widerspruch. Bei Diodor XXIV 1, 2 führt Adherbal die karthagischen Unterstützungstruppen nach Lilybaion (so auch bei Zonaras), bei Polyb I 44, $1(46,1)$ dagegen Hannibal, der Sohn Hamilkars und Freund Adherbels. Es könnte scheinen, als ob auch Orosius der Ueberlieferung Polybs folgte: IV, 10, 2 quod oppidum Romani obsidere conati superveniente Hannibale qui Hamilcaris filius fuit victi, maiore exercitus sui parte perdita ipsi aegre evaserunt, indessen ist es doch nicht unbedingt notwendig, diese Worte auf den gleichen Vorgang zu beziehen, wie die Worte Polybs. Hannibal brachte erst 249 anf 30 Schiffen Lebensmittel nach Drepana (Diod. XXIV 1, 6 'Avví $\beta \alpha v$

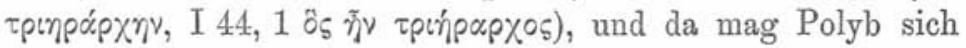


wohl eine einfache Verwechslung haben zu schulden kommen lassen.

Die Römer schnitten die Verbindung der Stadt durch einen Graben von Meer zu Meer ab (XXIV, 1, 1), dieselbe Situation

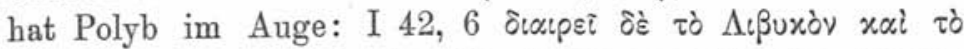

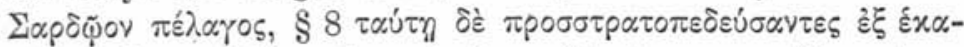

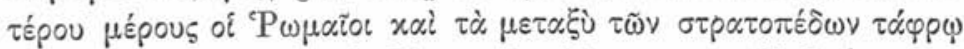

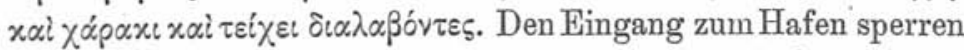
die Römer durch Versenken von Schiffen, die mit Steinen be-

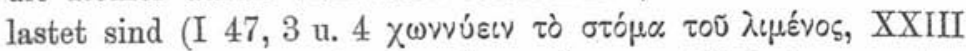

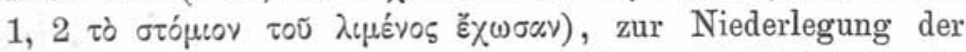
Mauern werden gewaltige Maschinen erbaut, die Diodor einzeln auffuhrt, während Polyb dies unterläßt (XXIV, 1, 1 und 3

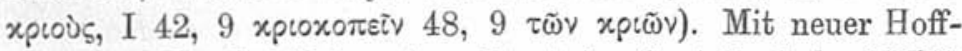
nung erfullt die Belagerten die Ankunft Adherbals (XXIV 1,2 und I 44, 5). Diodor hebt schärfer den Gang der Operationen hervor, während Polyb es vorzieht, einzelne Episoden der Belagerung zu erzählen (I 43. 44. 45. 46-47).

Auf Vorgänge, die einer früheren Zeit angehören, nimmt I 43, 2 Bezug; damit ist hier die Benutzung einer römischen Quelle ausgeschlossen. Es spricht hier (§ 8) unverkennbar ein Schriftsteller, dem die Angelegenheiten der Stadt Agrigent am Herzen liegen.

Der hellenische Standpunkt der benutzten Quelle macht sich in I 48, 3 bemerklich, wo vor allen den hellenischen Söldnern der Erfolg Himilkos zugeschrieben wird. Bei der Vernichtung der römischen Belagerungsmaschinen werden die Karthager durch einen heftigen Sturm unterstützt, der das Feuer rasch

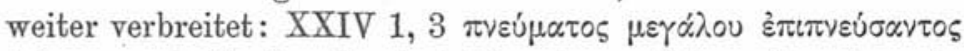

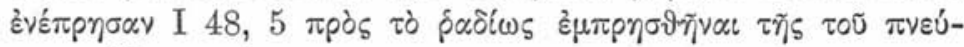

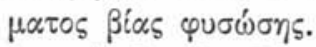

Auch die Darstellung des Zonaras steht den Berichten Diodors und Polybs nahe, und es hat den Anschein, als ob Dio Cassius in der Geschichte des Jahres 250/49 wieder der Quelle sich zugewandt habe, der er auch die ersten Verhandlungen des Jahres 264 nacherzählt hat; sicher gehört diese Partie (VIII 15. S. 217 u. 218) zu den besten Stücken der Kriegsgeschichte des Zonaras.

Philologus LX (N. F. XIV), 1. 
Mit c. 53 und 55 kehrt Polybius, nachdem er die Schlacht von Drepana nach römischer Quelle erzählt hat, zu Philinos zurück (s. S. 118) und ihm bleibt er, wie es scheint, auch c. 56-58 treu. Dafür sprechen die genauen Ortsangaben, das Hervortreten des Barkas, um dessen Person die ganze Erzählung sich dreht, die Polemik gegen Fabius (I 58, 4). Die anderen Schriftsteller übergehen diesen Kriegsabschnitt entweder ganz, oder von ihrer Erzählung ist fast nichts erhalten, sie setzt erst mit der Geschichte des Jahres 242 ein, als die Römer sich wieder zum Seekriege entschlossen.

Nach dem Modelle der Pentere des Rhodiers Hannibal bauen römische Privatleute eine Flotte von 200 Schiffen. Mit der Erwähnung dieses Mannes wird auf die ausführliche Erzählung in I 46 und 47 Bezug genommen, und wir werden durch diese Bezugnahme auf die dort benutzte Quelle auch in I 59 geführt.

Nach Zonaras VIII 15 (S. 218) hatte Claudius Pulcher die Pentere Hannos aus Karthago weggenommen, welche den Römern das Modell für den neuen Flottenbau lieferte. Die Zahl 200 ist wohl nicht richtig überliefert, alle anderen Berichte (Diod. XXIV 11, Eutrop II 27, Oros. IV 10, 5 und Aur. Victor c. 4) bieten übereinstimmend die Zahl 300. In seinen Verlustangaben hat Polyb weder Diodors Angaben, noch die Eutrops und des Orosius, steht aber dem ersteren doch näher als den anderen (Diod. XXIV, 11; Eutrop II 27, Oros. IV, 10, 7). So verlieren die Karthager nach Polyb 120 Schiffe, nach Diodor dagegen 127, der erstere giebt I 61, 6 abgerundete Zahlen. An Gefangenen büfiten sie nach der römischen Ueberlieferung 32000 Mann ein, nach Diodor dagegen, wie Philinos schreibt, 6000, wie andere berichten, 4400 Mann. Damit wufiste sich Polyb nicht abzufinden und setzte deshalb wieder die Zahl 10000 ein, die ihm wohl ungefähr das Richtige zu treffen schien: I 61,8 ou $\pi 0 \lambda \dot{\nu} \tau \tilde{\omega} \nu$

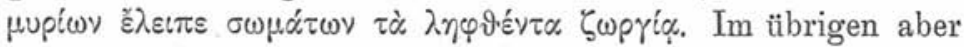
lassen Polybs und Diodors Darstellung den gemeinsamen Ursprung erkennen: 


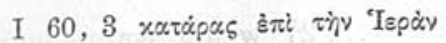

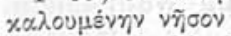

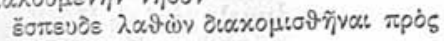

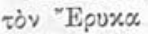

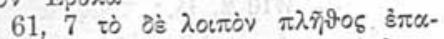

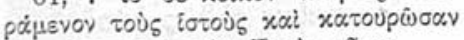

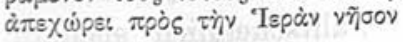

$\eta \bar{\eta} \lambda \mathrm{s}$

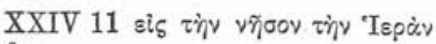

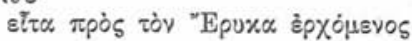

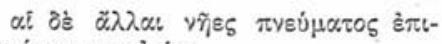

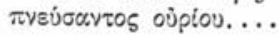

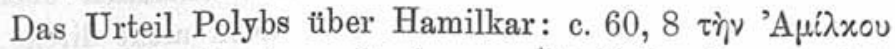

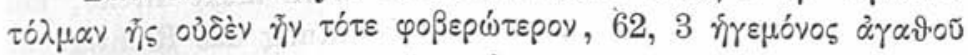

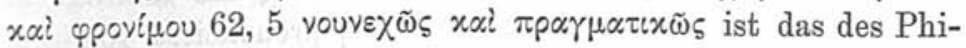
linos XXIV 5, 2. Die römisch-annalistische Ueberlieferung vertritt nachweislich wieder Zonaras (vgl. Val. Max. II 8, 2; Aur. Victor c. 41).

Polyb eilt zum Schlusse und teilt, über die Friedensverhandlungen rasch hinweggehend, nur die Bedingungen des Präliminarfriedens mit, während er III 27 den vom Volke abgeänderten Friedensvertrag bespricht. Die Bemerkungen, die er an den Friedensschlufs knüpft, sind teilweise dem Philinos entnommen (Diod. XXIII 15, 4), obwohl er gegen ihn polemisiert.

Beachtung verdient schließlich trotz mancher Entstellungen und Verwechslungen für die letzte Zeit die Darstellung Appians (Sicil. c. 2).

Wenn er auch über den Ausgang des Regulus an die römische Tradition sich anschliefst, so hat er doch die auffallende Uebereinstimmung mit Diodor darin, daf er erst am Ende des Kriegs von demselben spricht. Es kann dies kaum ein zufälliges Zusammentreffen sein, ich möchte vielmehr annehmen, dafs Appian die Darstellung des Philinos (Diod. XXIV 12) nicht fremd gewesen ist, daßs er sie aber ersetzte durch die ihm bekannte römische Ueberlieferung, dabei festhaltend an dem Jahre, in welches Philinos die unmenschliche Behandlung karthagischer Gefangener seitens der Atilier gesetzt hat.

Die Verluste der Römer und Karthager während des Kriegs berechnet Appian genau so, wie Polyb I 63; er kennt und benutzt Polyb (Libyca c. 132). Aus ihm könnten auch die Friedensstipulationen hergenommen sein, die teils nach den Bestimmungen des Präliminarfriedens, teils nach denen des definitiven Friedens gegeben werden, doch ist eine 
solche Kontamination aus I 62 und III 27 wenig wahrscheinlich, ja sie wird geradezu ausgeschlossen durch einige Zusätze,

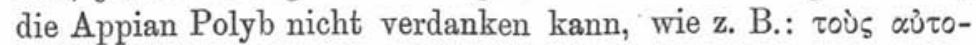

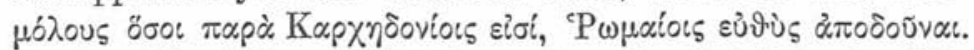
Appians Darstellung geht demnach wahrscheinlich ebenfalls auf Philinos zurück, wenn vielleicht auch nicht direkt, auf keinen Fall scheint mir Davins Beobachtung das Richtige zu treffen, wenn er Appians Bericht als prononciert römische Nationaltradition charakterisiert.

$$
* \quad * \quad *
$$

Um zum Schlusse noch einmal die Ergebnisse der versuchten Scheidung zwischen den aus Fabius und Philinos von Polyb entlehnten Stücken kurz zusammenzufassen, so sind dem römischen Gewährsmann wohl I 20-24, 7; 25, 5-30, 4; $32-34 ; 36-37,4 ; 39,2-6 ; 40-41,4,49-51$, dem griechischen dagegen I $10-19 ; 24,7-25,4 ; 30,5-31 ; 35$; $37,4-39,1 ; 39,7-15 ; 41,5-48 ; 52-64$ zuzuweisen.

Saarbrücken.

Friedrich Reuss. 